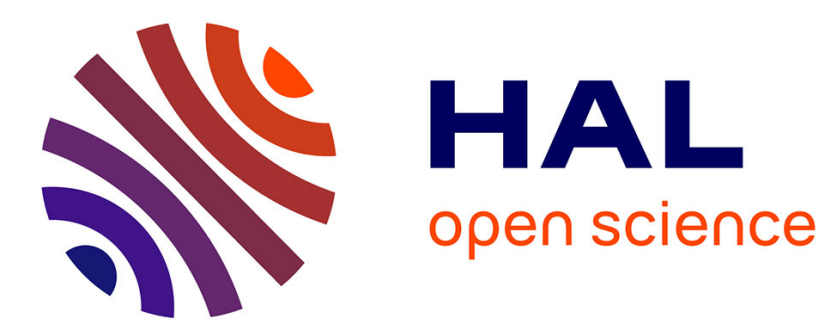

\title{
Induction machine faults detection using stator current parametric spectral estimation
}

El Houssin El Bouchikhi, Vincent V. Choqueuse, Mohamed Benbouzid

\section{To cite this version:}

El Houssin El Bouchikhi, Vincent V. Choqueuse, Mohamed Benbouzid. Induction machine faults detection using stator current parametric spectral estimation. Mechanical Systems and Signal Processing, 2014, pp.447-464. 10.1016/j.ymssp.2014.06.015 . hal-01079500

\section{HAL Id: hal-01079500 https://hal.science/hal-01079500}

Submitted on 4 Nov 2014

HAL is a multi-disciplinary open access archive for the deposit and dissemination of scientific research documents, whether they are published or not. The documents may come from teaching and research institutions in France or abroad, or from public or private research centers.
L'archive ouverte pluridisciplinaire $\mathbf{H A L}$, est destinée au dépôt et à la diffusion de documents scientifiques de niveau recherche, publiés ou non, émanant des établissements d'enseignement et de recherche français ou étrangers, des laboratoires publics ou privés. 


\title{
Induction Machine Faults Detection using Stator Current Parametric Spectral Estimation
}

\author{
El Houssin El Bouchikhi, ${ }^{1,2}$, Vincent Choqueuse ${ }^{1}$ and $\underline{\text { Mohamed Benbouzid }}^{1, *}$ \\ ${ }^{1}$ University of Brest, EA 4325 LBMS, Rue de Kergoat, CS 93837, 29238 Brest, \\ France \\ ${ }^{2}$ ISEN, EA 4325 LBMS, 20, Rue Cuirass Bretagne, 29200 Brest, France \\ *Corresponding author: Tel. +33298018007 - Fax: +33298016643 - Email: \\ Mohamed.Benbouzid@univ-brest.fr
}

\begin{abstract}
Current spectrum analysis is a proven technique for fault diagnosis in electrical machines. Current spectral estimation is usually performed using classical techniques such as periodogram (FFT) or its extensions. However, these techniques have several drawbacks since their frequency resolution is limited and additional post-processing algorithms are required to extract a relevant fault detection criterion. Therefore, this paper proposes a new parametric spectral estimator that fully exploits the faults sensitive frequencies. The proposed technique is based on the maximum likelihood estimator (MLE) and offers high-resolution capabilities. Based on this approach, a fault criterion is derived for detecting several fault types.

The proposed technique is assessed using simulation signals, issued from a coupled electromagnetic circuits approach-based simulation tool for mechanical unbalance and electrical asymmetry faults detection. It is afterward validated using experiments on a $0.75-\mathrm{kW}$ induction machine test bed for the particular case of bearing faults.
\end{abstract}

Keywords

Induction machine, faults detection, bearing faults, stator current, spectral estimation, maximum likelihood estimator.

\section{NOMENCLATURE}

$D F T=$ Discrete Fourier Transform;

$F F T=$ Fast Fourier Transform;

$E S P R I T=$ Estimation of Signal Parameters via Rotational Invariance Techniques;

$M L E \quad=$ Maximum Likelihood Estimator;

$M U S I C=$ Multiple Signal Classification;

$D F T=$ Discrete Fourier Transform;

$D S P \quad=$ Digital Signal Processing;

$M C M F T=$ Maximum Covariance Frequency Tracking;

$M D L=$ Minimum Description Length;

$P S D \quad=$ Power Spectral Density;

$S N R=$ Signal to Noise Ratio;

$f_{s} \quad=$ Stator supply frequency;

$s \quad=$ Per-unit slip;

$p \quad=$ Pole pair number. 


\section{INTRODUCTION}

Condition monitoring is of high concern in industrial applications since it minimizes the downtime and improves the reliability, availability, safety and productivity of these systems. For electrical motors and generators, faults detection is usually performed by vibration monitoring, temperature measurements, oil monitoring, flux monitoring and current analysis [1], [2]. Among these various techniques, current analysis has several advantages since it is a noninvasive technique that avoids the use of extra sensors [3]-[7]. Moreover, the electrical signals (for instance, the stator current) are usually available and inexpensive to measure.

Stator currents processing-based faults diagnosis of induction machine has received intense research interest for several decades [8]-[10]. Moreover, the International Standard "ISO FDIS 20958" dealing with "Condition monitoring and diagnostics of machine systems - Electrical signature analysis of three-phase induction motors" sets out guidelines for the online techniques recommended for the purposes of condition monitoring and diagnostics of machines, based on electrical signature analysis. Hence, many studies have shown that fault monitoring could be performed by supervising the current spectrum. In particular, it has been demonstrated that faults introduce additional spectral components in the stator current around the supply frequency [11], [12]. For a faulty machine, the frequency location of these components is given by $f_{k}(\Omega)$, where $f_{k}$ corresponds to the $k^{t h}$ component $(k \in \mathbb{Z})$, and $\Omega$ is a set of parameters that must be estimated in order to determine the induction machine health condition. These frequencies are associated with several mechanical and/or electrical faults such as air-gap eccentricity, bearing failures or broken rotor bars. For instance, In the case of broken rotor bars, the fault signature is given by

$$
f_{k}(\Omega)=f_{s}\left[k\left(\frac{1-s}{p}\right) \pm s\right]
$$

where $\Omega=\left\{s, f_{s}\right\}$.

Traditional current-based techniques for fault detection monitor the stator current spectrum and, more precisely, the fault characteristic frequencies [13]. In steady-state conditions, techniques based on conventional PSD estimators have been employed [14]. These techniques can be classified into two categories: non-parametric and parametric methods [15].

Non-parametric methods include the periodogram, which is usually implemented using the FFT, and its extensions. The classical periodogram have been applied for fault detection in [11], [12]. The main drawback of this technique relies on its performance. Indeed, even though the FFT is computationally efficient, it suffers from a poor frequency resolution (inversely proportional to the measurement time interval) and leakage effects (the energy of the main lobe leaks into sidelobes) due to windowing. Moreover, frequencies in the Discrete Fourier Transform (DFT) are spaced at intervals of $\frac{F_{s}}{N}$ where $F_{s}$ is the sampling frequency and $N$ is the length of the input time series. Attempting to estimate the amplitude of a sinusoid with a frequency that does not correspond to a DFT bin can result in an inaccurate estimate. Therefore, several DFT interpolation techniques have been proposed in order to enhance frequency accuracy such as analytical leakage compensation [16], zero-padding [15], phase interpolation estimator [17] and many others [18][20]. Furthermore, the periodogram method provides reasonably high resolution for sufficiently long data lengths, but it is a poor spectral estimator because its variance is high and does not decrease with increasing data length. In addition of that, it is often advantageous to use a window function other than a rectangular (natural) one and which has a Fourier transform with faster decaying side-lobes than sinc-type function. The multiplication of the data with a particular window function can reduce the sidelobe amplitudes but increases the width of the mainlobe. Common window functions are: the Bartlett window, Hamming window, Hanning window, and others [21]. The rectangular window leads to a narrow mainlobe but the highest sidelobes whereas the Hanning window reduces strongly the sidelobe amplitudes but leads 
to the largest mainlobe [22], [23]. Furthermore, the high variance of the periodogram method motivates the development of modified methods that have lower variance, at the cost of reduced resolution. Several modified methods have been introduced such as the Bartlett [24] and the Welch techniques [24], [25]. Moreover, the so-called Zoom-FFT (ZFFT) technique [26] has been introduced to improve the frequency accuracy in a specified frequency range without increasing the computational complexity. Nevertheless, the periodogram and its extensions suffer from a low frequency resolution, which is defined as the ability to distinguish two closely spaced frequency components. In [27], demodulation technique based on Hilbert transform was used to improve the frequency resolution of MCSA method for rotor asymmetries detection without concern about the signal nature (multi-component signal).

If an a priori signal model is assumed, parametric methods can be employed to improve the frequency resolution. These techniques are generally called high-resolution methods and include two sub-classes: the linear prediction methods and the subspace techniques. The linear prediction class contains several algorithms like the Prony and Pisarenko methods. The use of these methods for fault detection in electrical drives has been investigated in [28] and [29]. The subspace class includes the MUSIC and ESPRIT approaches. Applications for induction machine faults diagnosis are available in [2], [30]-[32]. In [33], the MUSIC algorithm and a zooming method were combined to reduce the computational cost of the spectral estimator. However these techniques are generally computationally intensive and lead to suboptimal estimators of the PSD. Moreover, their performance decrease significantly if the noise level increases.

In addition to the aforementioned techniques, many faults detection procedures based on statistical analysis of the current signal have been proposed such as MCMFT [34] and adaptive statistical Time-Frequency Methods [35] without presenting any fault detection criteria for an automatic fault diagnosis.

The above review emphasizes the compromise between frequency accuracy, frequency resolution, statistical performance and computational cost of spectrum analysis techniques for fault detection in induction machine. Furthermore, these previous techniques are general and do not exploit the particular structure of the stator current frequency components given in the existing works dealing with induction machine failure diagnosis. In order to illustrate the limitations of the classical spectrum analysis techniques, Fig 1 represents the current waveform and the spectrum using the periodogram, MUSIC and ESPRIT techniques in the case of a healthy and faulty motor (bearing fault). The simulation parameters for the periodogram are: sampling frequency $F_{s}=1000 \mathrm{~Hz}, N=2000$, a Hanning window, and a zero padding with $N_{\text {pad }}=4096$. The number of sinusoids for MUSIC and ESPRIT is setted equal to $L=6$ and $M+1$ by $M+1$ correlation matrix is computed with $M=\frac{N}{8}$. It is obvious that these techniques provide information about the presence of fault (sidebands-related fault) but no direct fault detection criterion is provided. Consequently, additional post-processing algorithms are required to determine the fault-related frequencies (mainly done manually) and to extract a fault detection criterion. Once the frequency spectrum is obtained and stored, empirical formula are used in order to reveal frequency signatures in the spectrum within various frequency ranges depending on the fault to be diagnosed. If predicted frequency patterns are present in the spectrum, a fault classification is achieved.

In this paper, in order to overcome the above mentioned limitations, we propose a parametric PSD estimator based on the MLE combined with minimum description length principle (MDL). In [36], a technique based on the MLE has been proposed for mechanical fault detection in induction machine. Nevertheless, this technique is limited to particular faults and its extension to other faults is far from trivial. Moreover, its implementation requires the use of sophisticated optimization tool. The fault detection algorithm proposed in this paper is composed of the two steps described in Fig. 2. First, the fault related frequencies number and the PSD are estimated by using the MLE combined with information theoretic criteria (MDL). This estimation 


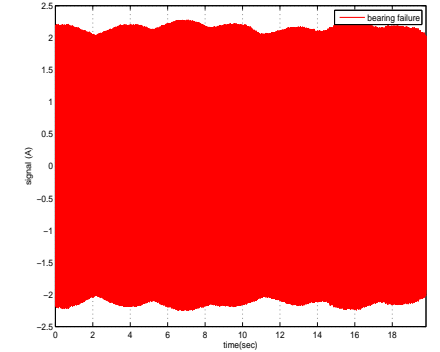

(a) Stator current waveform (b) (Faulty case).

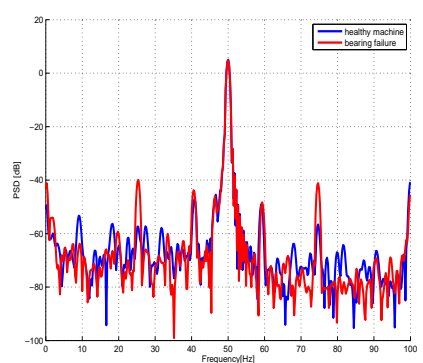

Periodogram-based (c) MUSIC-based pseudospec-

spectrum (Hanning window). trum.

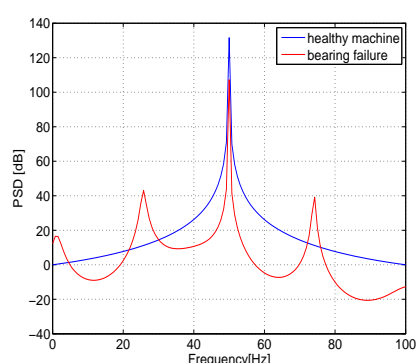

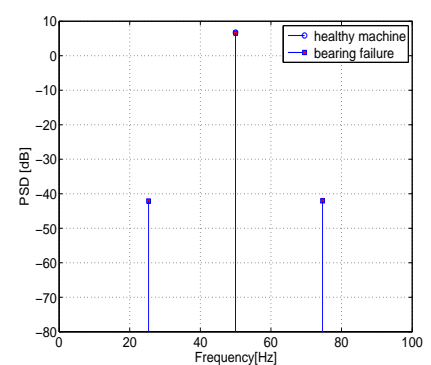

(d) ESPRIT-based spectrum.

Fig. 1 . Classical spectrum analysis techniques on experimental data.

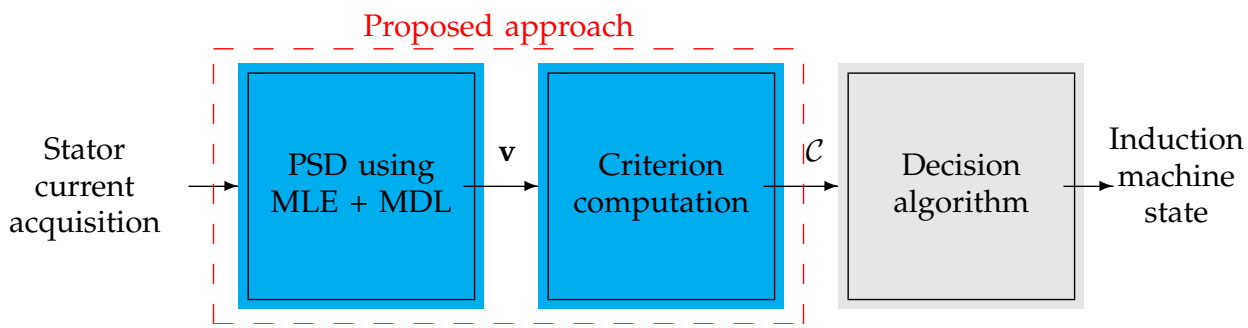

Fig. 2 . Block Diagram of the proposed technique. Symbol $\mathcal{C}$ corresponds to the fault detection criterion and $\mathbf{v}$ is a vector containing the estimated parameters of the monitored stator current.

algorithm implies a 3-D optimization problem if we consider the supply frequency unknown. Then, a simple fault criterion is computed from the amplitude estimate of the fault characteristic frequencies. The main advantage of the proposed method is its ability to automatically extract the fault frequency signature and to automatically compute a fault indicator without the need of an expert to interpret the current spectrum [37].

The major contributions of this paper are threefold:

- We propose a new model order and spectral estimation technique aiming at detecting the induction machine fault frequency signatures. This technique is asymptotically optimal and exhibits high-resolution capabilities.

- We demonstrate the appropriateness of the approach on major faults in induction machine. In fact, it makes a potential failure identifiable and quantifiable.

- We prove the effectiveness of the technique on simulated and experimental data.

The remaining parts of this paper are organized as follows.

- Section 2 introduces the signal model for healthy and faulty machines.

- Section 3 describes the proposed PSD estimator.

- Section 4 presents the fault detection criterion.

- Section 5 deals with the application of the proposed method for air-gap eccentricity, broken rotor bars, and bearing faults detection, which are the most frequent faults in electric machines according to [38], [39].

\section{STATOR CURRENT SIGNAL MODEL}

\subsection{Faults Effect on Stator Current Spectrum}

The induction machine is subjected to various failures that affect mainly three components : the stator, the rotor and/or the bearings (Fig. 3a). Recent papers dealing with induction machine faults distribution [39] have shown that bearings (69\%), stator windings (21\%), rotor (7\%), and 


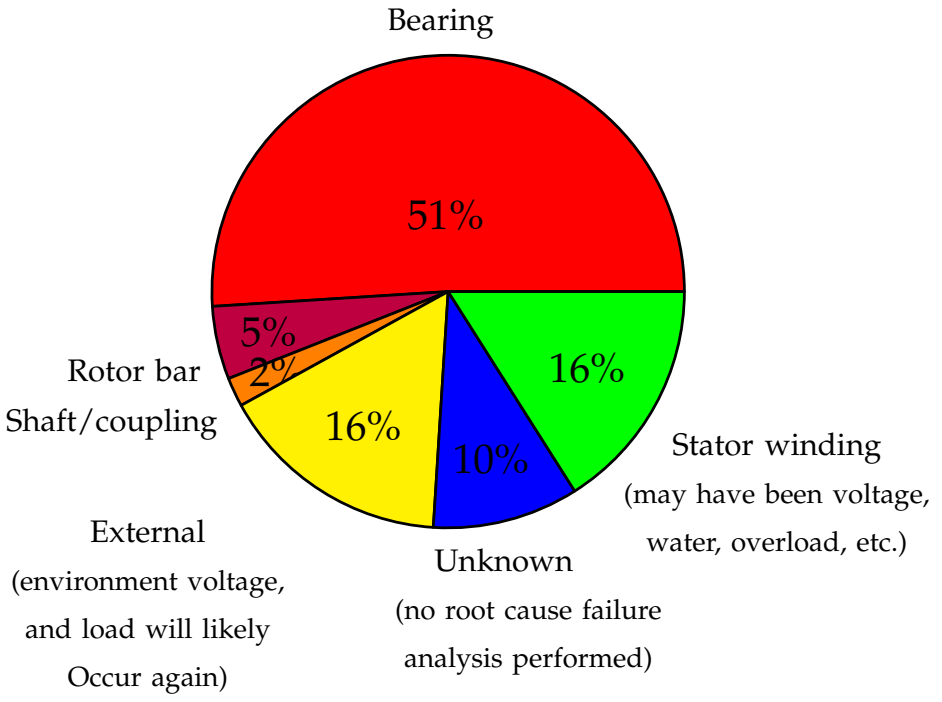

(a) Breakdown of failed components by distribution.

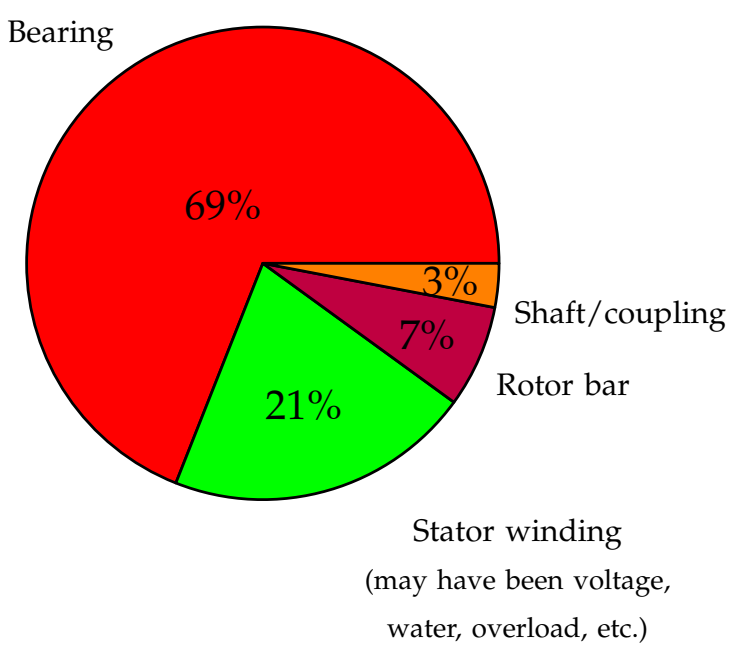

(b) Extrapolated distribution of failure by motor components.

Fig. 3 . Distribution of known motor failures for the petroleum and chemical industries [39].

Table 1 . Induction machine faults signatures [11], [12].

\begin{tabular}{|c||c||c||c|}
\hline $\begin{array}{c}\text { Induction } \\
\text { machine state }\end{array}$ & $\begin{array}{c}\text { Frequency } \\
\text { Signature }\end{array}$ & Parameters & $\Omega$ \\
\hline $\begin{array}{c}\text { Bearing } \\
\text { Damage }\end{array}$ & $\left|f_{s} \pm k f_{o}\right|$ & $k=1,2,3, \ldots$ & $\Omega=\left\{f_{s}, f_{0}\right\}$ \\
\hline Broken & $f_{s}\left[k\left(\frac{1-s}{p}\right) \pm s\right]$ & $\frac{k}{p}=1,3,5,7,11,13 \ldots$ & $\Omega=\left\{f_{s}, s\right\}$ \\
Rotor Bars & $f_{s}\left[1 \pm k\left(\frac{1-s}{p}\right)\right]$ & $k=1,2,3, \ldots$ & $\Omega=\left\{f_{s}, s\right\}$ \\
\hline $\begin{array}{c}\text { Air Gap } \\
\text { Eccentricity }\end{array}$ & $f_{s}\left[1 \pm k\left(\frac{1-s}{p}\right)\right]$ & $k=1,2,3, \ldots$ & $\Omega=\left\{f_{s}, s\right\}$ \\
\hline Load & & \\
\hline oscillation & &
\end{tabular}

shaft/coupling (3\%) are the most failing components (Fig. 3b). Most of the recent researches on induction machine faults detection has been directed toward electrical monitoring with emphasis on stator current supervision. In particular, the current spectrum is analysed to extract the frequency components introduced by the fault. A summary of induction machine faults effects on stator current is presented in Table 1 .

Where $f_{s}$ corresponds to the supply frequency, $s$ is the per unit slip, and $p$ is the pole-pair number. Symbol $f_{o}$ corresponds to one of the characteristic vibration frequencies introduced by bearing fault which depends on the bearing dimensions and mechanical rotor frequency [40]. In [41], it has been demonstrated that depending on the physical phenomena (eccentricity or torque variations) introduced by bearing faults, the corresponding frequency signatures are different. Moreover, these signatures depends on the defected components. Concerning the load oscillation, the model presented holds only if the load oscillates at the rotating frequency [41], [42]. In fact, in the case of load oscillations, the stator current is modulated by the shaft rotational speed, 
belt pass frequency, compression frequency, blades rotational frequency, meshing frequency, resonance frequency of the control loop, etc. Finally, concerning the eccentricity fault, we only focus on the monitoring of the current at the fundamental sidebands of the supply frequency given in [11]. In fact, since space harmonics are usually of smaller amplitude, higher order terms of these harmonics can be supposed to be less affected by the fault than the fundamental frequency. In general way, the fault detection methods monitors the behavior of the current at the sidebands of the slot frequencies. These sidebands associated with eccentricity are given in [9].

The frequencies given by Table 1 are used in the faulty induction machine stator current model described in the following section. When a fault occurs, the amplitude at these frequencies increases and reveal abnormal operating conditions.

\subsection{Induction Machine Stator Current Signal Model}

The stator current signal model is based on the following assumptions:

- $\mathcal{H}_{1}$ : The received signal is modeled as a sum of $2 L+1$ sine waves embedded in noise. $2 L$ corresponds to the number of the sidebands around the supply frequency introduced by the fault (whose amplitudes rise when a fault occurs).

- $\mathcal{H}_{2}$ : The noise is white, Gaussian with zero-mean and variance $\sigma^{2}$.

- $\mathcal{H}_{3}$ : The signal frequency content obeys to the particular structures given by Table 1 .

- $\mathcal{H}_{4}$ : The matrix $A(\Omega)$ has full column rank $2 \times L+1$, i.e. $\operatorname{rank}(A(\Omega))=2 L+1$. This is verified for $N>2 L+1$.

In practice, $\mathcal{H}_{1}$ may not be verified since the induction machine stator current may contain space- and time-harmonics. However, some of these harmonics can be eliminated by filtering the stator current signal in order to focus on the fault-affected frequency bandwidth. Moreover, we must note that $\mathcal{H}_{1}$ requires the knowledge of $L$. In the present work, we propose a technique to estimate it from the stator current signal. Concerning the assumption $\mathcal{H}_{2}$, it is not particularly restrictive. In fact, if the noise process is not white and has unknown spectral shape, then accurate frequency estimates can still be found if we estimate the sinusoids using the non-linear least squares (NLS) [15, Chapter 4, Introduction].

Under the assumption $\mathcal{H}_{1}-\mathcal{H}_{3}$, the stator-current samples $x[n]$ can be expressed as

$$
x[n]=\sum_{k=-L}^{L} a_{k} \cos \left(2 \pi f_{k}(\Omega) \times\left(\frac{n}{F_{s}}\right)+\phi_{k}\right)+b[n]
$$

where $b[n]$ corresponds to the noise sample. Symbols $f_{k}(\Omega), a_{k}$ and $\phi_{k}$ correspond to the frequency, the amplitude and the phase of the $k^{t h}$ frequency component, respectively. Symbol $F_{s}$ corresponds to the sampling rate. Note that the particular case where $k=0$ corresponds to the fundamental frequency component.

The PSD is defined as the Discrete Time Fourier Transform of the covariance function of $x[n]$ [15]. Under the assumption $\mathcal{H}_{2}$ and that the initial phases $\phi_{k}$, are independent random variables uniformly distributed on $[-\pi \pi]$, the theoretical PSD of $x[n]$ is given by Fig. 4 [15]. In practice, the PSD is unknown, and must be estimated from $N$ samples. Using a matrix notation, $x[n](n=0, \cdots, N-1)$ can be expressed as

$$
\mathbf{x}=\mathbf{A}(\Omega) \mathbf{v}+\mathbf{b}
$$

where:

- $\mathbf{x}=[x[0], \cdots, x[N-1]]^{T}$ is a $N \times 1$ column vector containing the stator current samples,

- $\mathbf{b}=[b[0], \cdots, b[N-1]]^{T}$ is a $N \times 1$ column vector containing the noise samples, 


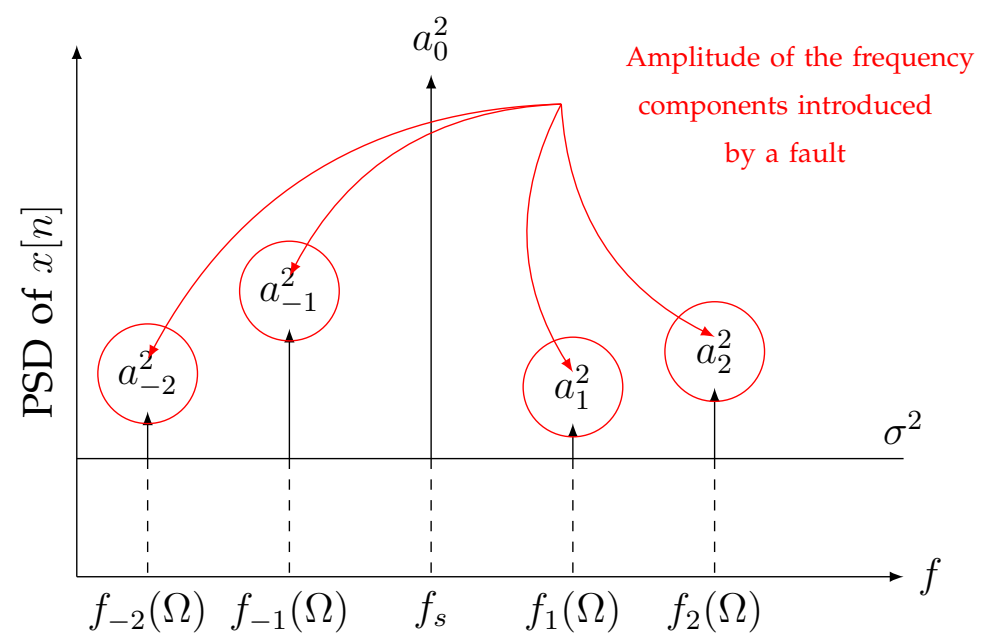

Fig. 4 . Theoretical PSD for $L=2$ [15].

- $\mathbf{v}$ is a $2(2 L+1) \times 1$ column vector containing the amplitudes and phases of the characteristic fault frequencies. This vector is given by

$$
\mathbf{v}=\left[a_{-L} \cos \left(\phi_{-L}\right) \ldots a_{L} \cos \left(\phi_{L}\right),-a_{-L} \sin \left(\phi_{-L}\right) \ldots-a_{L} \sin \left(\phi_{L}\right)\right]^{T}
$$

$\mathbf{A}(\Omega)$ is a $N \times 2(2 L+1)$ matrix whose elements are given by

$$
\mathbf{A}(\Omega)=\left[\mathbf{z}_{-L} \ldots \mathbf{z}_{L}, \mathbf{y}_{-L} \ldots \mathbf{y}_{L}\right]
$$

where

$$
\begin{aligned}
& \mathbf{z}_{k}=\left[1 \cos \left(2 \pi f_{k}(\Omega) \times \frac{1}{F_{s}}\right) \ldots \cos \left(2 \pi f_{k}(\Omega) \times \frac{N-1}{F_{s}}\right)\right]^{T} \\
& \mathbf{y}_{k}=\left[0 \sin \left(2 \pi f_{k}(\Omega) \times \frac{1}{F_{s}}\right) \ldots \sin \left(2 \pi f_{k}(\Omega) \times \frac{N-1}{F_{s}}\right)\right]^{T}
\end{aligned}
$$

Non-parametric estimators estimate the PSD from $\mathbf{x}$ without using any a priori knowledge about the signal. Departing from this approach, we propose a parametric estimator that exploits the signal model in (3) and the fault related frequency presented in Table 1. In this context, the computation of the current spectrum from stator current samples $\mathbf{x}$ is treated as a statistical estimation problem. The main object is to estimate the parameters $\Omega$ in Table 1 and a relevant fault detection criterion.

\section{PARAMETRIC PSD ESTIMATION}

In this section, we present the fault detection scheme based on the MLE. The MLE is an asymptotically optimal estimator since it has the asymptotic properties of being unbiased, achieving the Cramer-Rao lower bound, and having a Gaussian Probability Density Function [43]. Application for PSD estimation has been investigated for harmonic and non-harmonic signal models in [44] and [45], respectively. Unfortunately, the MLE has a higher computational cost since it requires the optimization of a cost-function in high dimensional space. In the case of induction machine fault detection, we demonstrate that the MLE is computationally efficient since it leads to a 2-D optimization problem that is easy to implement. Besides, an efficient implementation of the 
MLE requires the knowledge of frequency components numbers which is called model order estimation problem. In order to estimate the model order (fundamental frequency and $2 \times L$ sidebands produced by fault, where $L$ has to be estimated), we propose to combine the MLE with an order-dependent penalty term based on the MDL principle [46]. It must be emphasized that the sidebands number $(2 \times L)$ estimation is of great interest since it contribute to inform us about the fault existence. Moreover, if the order is not estimated (chosen) correctly, the fault characteristic frequency may erroneously be estimated at, for example, half or double of the true value. In addition to the exact MLE, we propose an FFT-based approximate approach that leads to significant computational complexity reduction.

\subsection{Proposed Estimator}

The MLE is used in order to estimate $\mathbf{v}$ and $\Omega$. Then a penalty term is applied to the MLE cost function in order to estimate the model order i.e. $L$.

\subsubsection{Estimate of $\boldsymbol{v}$ and $\Omega$}

The ML estimator of $\mathbf{v}$, and $\Omega$ is given by

$$
\{\widehat{\mathbf{v}}, \widehat{\Omega}\}=\arg \max _{\mathbf{v}, \Omega} \log (p(\mathbf{x} ; \mathbf{v}, \Omega))
$$

where $p(\mathbf{x} ; \mathbf{v}, \Omega)$ is the probability density function (pdf) of $\mathbf{x}$ which is given by

$$
p(\mathbf{x} ; \mathbf{v}, \Omega)=\frac{1}{\left(2 \pi \sigma^{2}\right)^{\frac{N}{2}}} \times \exp \left[-\frac{1}{2 \sigma^{2}}(\mathbf{x}-\mathbf{A}(\Omega) \mathbf{v})^{T}(\mathbf{x}-\mathbf{A}(\Omega) \mathbf{v})\right]
$$

where $(.)^{T}$ denotes the matrix transpose, and a noise is considered white Gaussian noise with zero mean and variance equal to $\sigma^{2}$ i.e. $b[n] \sim \mathcal{N}\left(0, \sigma^{2}\right)$. The $\mathrm{ML}$ estimates of $\Omega$ and $\mathbf{v}$ are obtained by maximizing the pdf with respect to the unknown parameters. The maximization in (7) is equivalent to the minimization of the following cost function:

$$
\mathcal{L}(\mathbf{x} ; \mathbf{v}, \Omega)=(\mathbf{x}-\mathbf{A}(\Omega) \mathbf{v})^{T}(\mathbf{x}-\mathbf{A}(\Omega) \mathbf{v})
$$

Differentiating $\mathcal{L}(\mathbf{x} ; \mathbf{v}, \Omega)$ with respect to $\mathbf{v}$ and setting the derivative equal to 0 leads to the ML estimate of $\mathbf{v}$ denoted $\widehat{\mathbf{v}}$ (see Appendix $\mathrm{A}$ for the proof).

$$
\widehat{\mathbf{v}}=\mathbf{A}^{\dagger}(\Omega) \mathbf{x}
$$

where $\mathbf{A}^{\dagger}(\Omega)$ is the pseudo-inverse of $\mathbf{A}(\Omega)$ i.e.

$$
\mathbf{A}^{\dagger}(\Omega)=\left(\mathbf{A}^{T}(\Omega) \mathbf{A}(\Omega)\right)^{-1} \mathbf{A}^{T}(\Omega)
$$

and where $(.)^{-1}$ corresponds to the matrix inverse.

The ML estimate of $\Omega$ is obtained by minimizing $\mathcal{L}(\mathbf{x} ; \widehat{\mathbf{v}}, \Omega)$ with respect to $\Omega$. By replacing $\mathbf{v}$ by $\widehat{\mathbf{v}}$ in (9), we obtain (see Appendix B):

$$
\{\widehat{\Omega}\}=\arg \max _{\Omega} \mathcal{J}(\Omega)
$$

where:

$$
\mathcal{J}(\Omega)=\mathbf{x}^{T} \mathbf{A}(\Omega) \mathbf{A}^{\dagger}(\Omega) \mathbf{x}
$$




\subsubsection{Estimate of model order $L$}

The estimation of $L$ enhances the performance of the ML estimates of $\Omega$. The information theoretic criteria are used to estimate $L$ [47]. In fact, a penalty term based on MDL principle is applied to the MLE cost function in order to estimate $L$. Hence, the estimation of $L$ can be performed by maximizing the penalized ML estimate of $\Omega$ [46] as follows

$$
\{\widehat{\Omega}, \widehat{L}\}=\arg \min _{\Omega, L}\left(-2 \log p\left(\mathbf{x}, \widehat{\mathbf{v}}, \widehat{\sigma}^{2}, \Omega, L\right)+c(g, N)\right)
$$

where:

- The noise variance estimate is given by

$$
\widehat{\sigma}^{2}=\frac{1}{N}\|\mathbf{x}-\mathbf{A}(\widehat{\Omega}) \widehat{\mathbf{v}}\|
$$

- The penalty function $c(g, N)$ depends on the number of free parameters $g$ and the number of data samples $N$. Under the assumption that the number of the components is equal to $2 L+1, g=4 L+4$. The criterion information rule used within this paper is the minimum description length (also called the Bayesian Information Criterion Rule) [46] and is given by

$$
c(g, N)=g \log (N)
$$

A straightforward computation leads to the following optimization problem (see Appendix C for the proof):

$$
\{\widehat{\Omega}, \widehat{L}\}=\arg \max _{\Omega, L}-\left(\mathbf{x}^{T} \mathbf{x}-\mathcal{J}(\Omega)\right) \times \exp \left(\frac{c(g, N)}{N}\right)
$$

Finally, the PSD estimate of the stator current is composed of two steps: a) the estimates of $\Omega$, and $L$ are obtained from $(17)$, and $\mathrm{b}$ ) the vector $\mathbf{v}$ containing the amplitude and the phase of the fault characteristic frequencies is estimated by replacing $\Omega$, and $L$ with its estimates in (10). Because of its statistical properties, one should note that the Maximum Likelihood estimate remains the most accurate method for PSD estimation even in those cases where the noise is colored [15]. In particular, this estimator overcomes the frequency resolution limitation of the periodogram. Furthermore, as opposed to other techniques, the proposed approach exploits the faults characteristic frequencies to improve the accuracy of the PSD estimate.

About the implementation, the main difficulty relies on the optimization problem in (17). As the maximum can not be found analytically, numerical method should be used to estimate $\Omega$ and $L$. In our context, the cost function is only composed of three parameters, which implies a maximization in a 3-D space. The search space is relatively limited since the variation range of $\Omega$ and $L$ are approximately known. For these reasons, we propose to perform the maximization of (17) with a grid-search algorithm. This algorithm evaluates the cost function at the vertices of a rectangular grid, and chooses the vertex with the highest value. It should be noted that the maximization step could be computationally demanding since it requires the construction and the inversion of a large matrix for each vertex of the grid.

For grid connected induction machine, the fundamental frequency can be assumed to be known. Consequently, the optimization problem in (17) reduces to 2-D problem. Figure 5a illustrates the maximization step for a synthetic signal with $f_{k}(\Omega)=f_{s} \pm k f_{c}, f_{s}=50 \mathrm{~Hz}, f_{c}=1 \mathrm{~Hz}$, $L=1$, and $\mathrm{SNR}=50 \mathrm{~dB}$. The acquisition time and the sampling frequency are equal to $1 \mathrm{~s}$ and $F_{s}=600 \mathrm{~Hz}$, respectively. The grid search algorithm evaluates the cost function for $f_{c}$ ranging from $0 \mathrm{~Hz}$ to $2 \mathrm{~Hz}$ with a step size of $0.001 \mathrm{~Hz}$ and $L$ varying from 0 to 4 . By looking at Fig. 5a, it can be observed that the cost function is maximized for the true values of $f_{c}$ i.e. $1 \mathrm{~Hz}$ and $L=1$. Concerning the computational complexity, the evaluation of the cost function requires $26.7 \mathrm{~s}$ on a HP ProBook PC at $2.2 \mathrm{Ghz}$, using Matlab-simulink ${ }^{\circledR}$. 


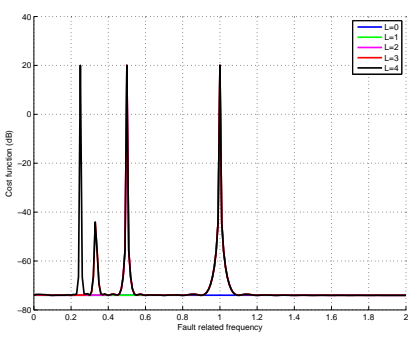

(a) $\mathcal{J}\left(f_{c}\right)(N=500)$.

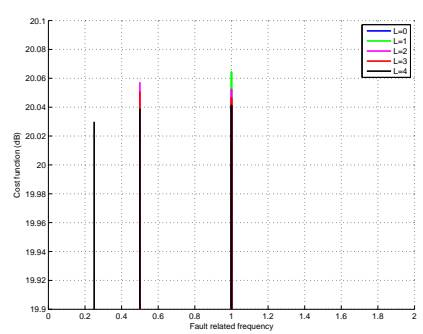

(b) $\mathcal{J}\left(f_{c}\right)$ (Zoom).

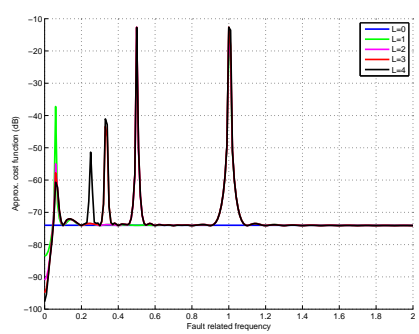

(c) $\mathcal{J}_{a}\left(f_{c}\right)(N=2000)$.

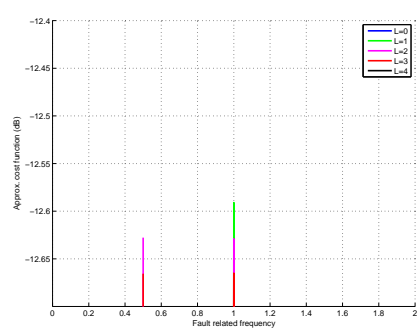

(d) $\mathcal{J}_{a}\left(f_{c}\right)$ (zoom).

Fig. 5 . Exact and approximate cost function $\left(f_{s}=50 \mathrm{~Hz}, f_{c}=1 \mathrm{~Hz}, L_{o p t}=1, F_{s}=1 k H z\right.$ and $\left.S N R=50 d B\right)$.

\subsection{Link with FFT}

The computational complexity of the PSD estimator can be reduced when the number of samples, $N$, goes to infinity. Indeed, by using the following limit (see, e.g., [43, Example 7.16]).

$$
\lim _{N \rightarrow \infty} \frac{2}{N}\left(\mathbf{A}^{T}(\Omega) \mathbf{A}(\Omega)\right)=\mathbf{I}_{N}
$$

where $\mathbf{I}_{N}$ corresponds to the $N \times N$ identity matrix. The cost function can be approximated as (see Appendix D)

$$
\mathcal{J}_{a}(\Omega)=\lim _{N \rightarrow \infty} \mathcal{J}(\Omega)=\frac{2}{N} \mathbf{x}^{T} \mathbf{A}(\Omega) \mathbf{A}^{T}(\Omega) \mathbf{x}=2 \sum_{k=-L}^{L}\left|\frac{1}{\sqrt{N}} \sum_{n=0}^{N-1} x[n] e^{-2 j \pi\left(f_{k}(\Omega)\right) \frac{n}{F_{s}}}\right|^{2}
$$

where the last equality comes from the fact that $x[n] \in \mathbb{R}$. The last equation can be expressed according to the Discrete Fourier Transform (DFT) of $x[n]$. Indeed,

$$
\mathcal{J}_{a}(\Omega)=2 \sum_{k=-L}^{L}\left|D F T_{x}\left[f_{k}(\Omega) / F_{s}\right]\right|^{2}
$$

where $D F T_{x}[f]$ is the DFT computed at frequency $f$ i.e.

$$
D_{F T}[f]=\frac{1}{\sqrt{N}} \sum_{n=0}^{N-1} x[n] e^{-2 j \pi f n}
$$

Finally the approximate ML estimate of $\Omega$ is simply obtained by replacing $\mathcal{J}(\Omega)$ with $\mathcal{J}_{a}(\Omega)$ in (12). It must be stressed that an approximate MLE can be obtained if $f_{k}(\Omega) / F_{s}$ is not close to 0 and $1 / 2$.

Similarly, the approximate ML estimator of the vector $\mathbf{v}$ is then computed using (22).

$$
\widehat{\mathbf{v}}=\frac{2}{N} \mathbf{A}^{T}(\Omega) \mathbf{x}
$$

This approximate approach can be extended in order to estimate the model order $L$ as follows

$$
\{\widehat{\Omega}, \widehat{L}\}=\arg \max _{\Omega, L}-\left(\mathbf{x}^{T} \mathbf{x}-\mathcal{J}_{a}(\Omega)\right) \times \exp \left(\frac{c(g, N)}{N}\right)
$$

Equations (23) and (20) show that the approximate cost function is reduced to a sum of DFT bins. This makes the approximate approach attractive for the following reasons: a) Most DSPboards include functions for DFT computation b) the DFT can be efficiently computed using the FFT. However, it should be stressed that the accuracy of the approximation highly depends 
on the signal length $N$. In particular, the approximation in $(18)$ is no longer valid for short signals. In this case, the DFT of the stator current signal exhibits sidelobes which affect the frequency resolution. The sidelobes can mask components close in frequency and then lead to false conclusions. Moreover, the sidelobes could be interpreted as fault characteristic frequency and then lead to false alarm. This may be overcame by choosing different windows (Hanning, Blackman) in order to attenuate sidelobes [23]. Moreover, interpolating the DFT by zero padding the data can often increase the frequency accuracy and thus improve the amplitude estimate [15]. The approximated method is then limited by the FFT algorithm resolution: the parameters are estimated correctly as long as the observed signal length $\frac{N}{F_{s}}$ is large enough compared to the inverse of the smallest frequency difference between two neighbouring poles of the signal i.e. (24).

$$
N \gg \frac{1}{\min _{k_{1} \neq k_{2}}\left|f_{k_{2}}-f_{k_{1}}\right|}
$$

Figure $5 \mathrm{c}$ illustrates the cost function for synthesized signal. One can notice that the exact cost function in Fig. $5 \mathrm{a}$ and its approximation in Fig. $5 \mathrm{c}$ have roughly the same shape and differ only in low frequencies and while $\left|f_{s} \pm k f_{c}\right| \rightarrow 0$. Indeed, these two shapes differs when the signal model contains closely spaced frequencies. For closely spaced frequencies, the resolution limitation of the DFT leads to wrong results. In particular in Fig. 5c, one can notice the spurious peak located at $f_{c}=0 \mathrm{~Hz}$. When using the approximate approach, spurious peaks must be removed to obtain accurate estimate of $f_{c}$. This can be done by excluding small values of $f_{c}$ from the grid search. Despite this drawback, the approximate approach is quite attractive since it leads to a drastic computational reduction. For example, the evaluation of the approximate cost function in Fig. $5 \mathrm{c}$ requires only 4.2s, while the evaluation of the exact one in Fig. $5 \mathrm{a}$ requires $26.7 \mathrm{~s}$.

\section{FAULT DETECTION CRITERION}

In this section, we propose a fault detection criterion based on the amplitude of the fault characteristic frequencies. As the PSD estimate directly exploits the fault signature, we show that the fault detection criterion can be easily derived from the vector $\widehat{\mathbf{v}}$.

\subsection{Proposed Criterion}

In order to successfully perform fault detection, a fault criterion is needed to measure the machine state. As the information about the fault severity is carried out by $a_{k}(k \neq 0)$, we propose to compute the sum of the squares of the (normalized) amplitude of the fault characteristic frequencies. This criterion is expressed mathematically as

$$
\mathcal{C}=\sum_{k=-L, k \neq 0}^{L}\left(\frac{a_{k}^{2}}{a_{0}^{2}}\right)
$$

This criterion exhibits the two following desirable properties.

Property 1: For healthy machines, the criterion is equal to 0 i.e.

$$
\mathcal{C}=0
$$

Property 2: The proposed criterion is invariant to scale. Indeed, let us denote $\mathcal{C}_{x}$ the fault criterion relative to the stator current $x[n]$. It can be demonstrated that the fault criterion $\mathcal{C}_{\alpha x}$, relative to the signal $\alpha x[n](\alpha>0)$, is equal to:

$$
\mathcal{C}_{\alpha x}=\mathcal{C}_{x}
$$




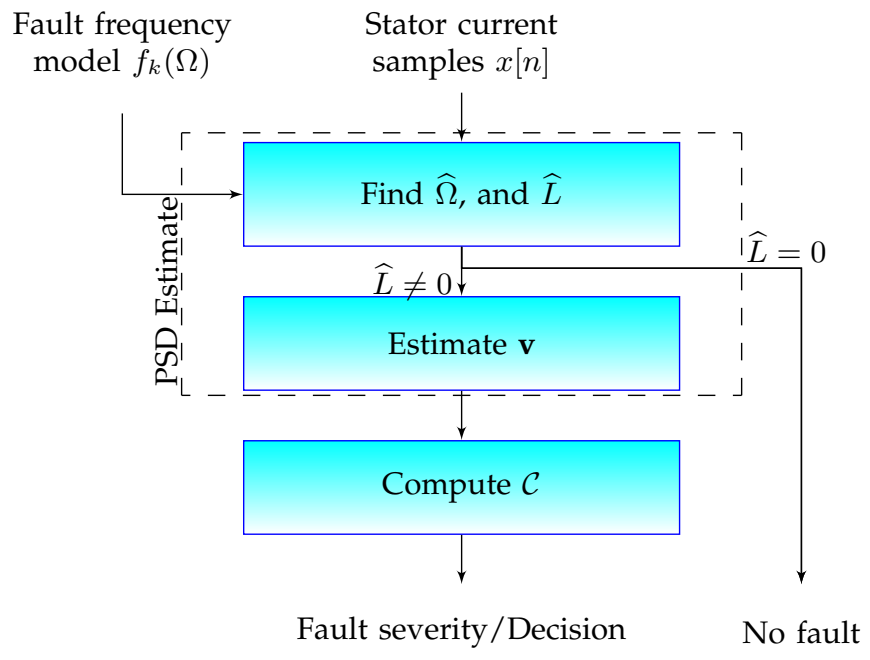

Fig. 6 . Fault detection algorithm.

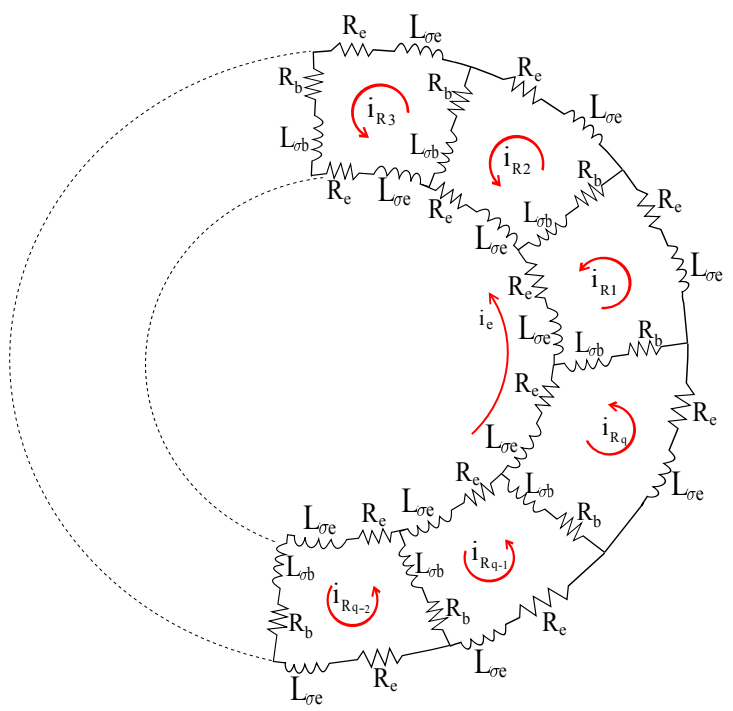

Fig. 7 . Rotor bars equivalent circuit [14].

The proposed criterion in (25) depends on the amplitudes $a_{k}(k=-L, \cdots, L)$. Once the PSD is estimated, $a_{k}$ can be extracted from the vector $\mathbf{v}$. However, using the structure of $\mathbf{v}$ in (4), it can be shown that $\mathcal{C}$ can be obtained directly from $\mathbf{v}$ without computing $a_{k}$. Indeed, the fault criterion in (25) can be expressed under the following matrix form (see the appendix E for proof):

$$
\mathcal{C}=\frac{\mathbf{v}^{T} \mathbf{v}}{\mathbf{v}^{T} \mathbf{M} \mathbf{v}}-1
$$

where $\mathbf{M}$ is a $(4 L+2) \times(4 L+2)$ matrix which is given by

$$
\left[\begin{array}{cc}
\mathbf{E}_{L+1, L+1} & \mathbf{0} \\
\mathbf{0} & \mathbf{E}_{L+1, L+1}
\end{array}\right]
$$

and where $\mathbf{E}_{u, v}$ is the $(2 L+1) \times(2 L+1)$ elementary matrix which is 1 in the $u^{\text {th }}$ row and $v^{\text {th }}$ column and is zero elsewhere. In practice, one should note that $\mathbf{v}$ is unknown and must be replaced by its estimate $\widehat{\mathbf{v}}$ in (28) to compute $\mathcal{C}$.

\subsection{Algorithm Summary}

The fault detection algorithm is summed up in Fig. 6. This algorithm can be implemented for real-time monitoring of an induction machine. Compared to other PSD-based monitoring technique (Periodogram, MUSIC, ESPRIT), the proposed approach is quite attractive since the vector $\mathbf{v}$ directly conveys information about the characteristic frequencies.

\section{APPLICATION TO INDUCTION MACHINE FAULTS DETECTION}

The proposed approach has been implemented in Matlab-Simulink ${ }^{\circledR}$ on a HP ProBook PC at 2.2 Ghz with 2 Go of RAM. Its performance is evaluated with simulated stator currents for eccentricity and broken rotor bars faults and experimental data for bearing failures.

\subsection{Simulation Results}

This section deals with the performance of the proposed approaches for induction machine faults detection. The induction machine modeling is briefly presented, then the proposed approaches are used to detect eccentricity and broken rotor bars faults. 


\subsubsection{Induction machine modeling}

An induction machine model for healthy and faulty machines has been developed based on the coupled magnetic circuits theory [13], [48], [49]. This method is based on the following assumptions:

- Negligible saturation;

- Negligible eddy current, friction and windage losses;

- Insulated rotor bars.

The induction machine stator consists of three phase concentric winding. Each winding is considered as a separated coil. The cage rotor has $n$ bars which can be described as $n$ identical and equally spaced rotor loops; each loop is formed by two adjacent rotor bars connected by the end-ring portions.

The rotor cage equivalent circuit showing the rotor loops and different currents is displayed in Fig. 7

The stator currents are obtained by solving the system of differential equations in (30).

$$
\left\{\begin{array}{l}
\frac{d}{d t} \mathbf{I}=-\mathbf{L}^{-1}\left(\mathbf{R}+\Omega \frac{d}{d \theta_{m}} \mathbf{L}\right) \mathbf{I}+\mathbf{L}^{-1} \mathbf{V} \\
\frac{d}{d t} \Omega=\frac{1}{2 J} \mathbf{I}^{T}\left(\frac{d}{d \theta_{m}} \mathbf{L}\right) \mathbf{I}-\frac{f}{J} \Omega-\frac{1}{J} \Gamma_{C} \\
\frac{d}{d t} \theta_{m}=\Omega
\end{array}\right.
$$

where :

$$
\begin{array}{cc}
\mathbf{V}=\left[\begin{array}{c}
\mathbf{V}_{s} \\
\mathbf{0}
\end{array}\right] & \mathbf{I}=\left[\begin{array}{l}
\mathbf{I}_{s} \\
\mathbf{I}_{r}
\end{array}\right] \\
\mathbf{R}=\left[\begin{array}{cc}
\mathbf{R}_{s} & \mathbf{0} \\
\mathbf{0} & \mathbf{R}_{r}
\end{array}\right] \quad \mathbf{L}=\left[\begin{array}{ll}
\mathbf{L}_{s s} & \mathbf{L}_{s r} \\
\mathbf{L}_{r s} & \mathbf{L}_{r r}
\end{array}\right]
\end{array}
$$

Symbols $\mathbf{V}_{s}, \mathbf{I}_{s}$ and $\mathbf{I}_{r}$ correspond to the stator voltage vector, the stator current vector and the rotor current vector, respectively. Inductances $\mathbf{L}_{s s}, \mathbf{L}_{r r}, \mathbf{L}_{r s}$ and $\mathbf{L}_{s r}$ correspond to the self and mutual inductances between stator windings and rotor windings. Resistances $\mathbf{R}_{s}$ and $\mathbf{R}_{r}$ refer to the stator and cage resistances and $\Gamma_{C}, \Omega$ and $\theta_{m}$ correspond to the load torque, the rotor mechanical speed and the rotor angular position, respectively. Finally, $J$ is the rotating masses inertia and $f$ is the viscous friction coefficient.

In (30), the machine inductances $\mathbf{L}$ are carried out using the air-gap magnetic energy, which is determined by means of the actual geometry and winding layout of the machine. A Matlabsimulink ${ }^{\circledR}$-based tool for faulty induction machines has been developed to generate faults database and therefore to allow testing the proposed faults detection approach.

In these simulations dynamic eccentricities are introduced to emulate a bearing fault. It has been demonstrated that single-point bearings faults have an effect over the machine eccentricity and/or load variations [40]-[42], [50]. In fact, bearing fault will induce mechanical eccentricities, but also load-torque variations. Hence, in the carried-out simulations, bearing faults are emulated by generating only one sort of physical phenomena: rotating eccentricities at bearing characteristic fault frequency $f_{c}$. These eccentricities leads to periodical changes in the induction machine inductances [40]. Moreover, broken rotor bars are emulated by suppressing the corresponding broken rotor bar.

Therefore, a $4 \mathrm{~kW}$ induction machine operating under nominal load condition have been simulated. Three machines have been considered: a healthy machine, a faulty one affected by a $10 \%$ (static, dynamic and mixed) eccentricity, and a faulty one affected by broken rotor bars. Simulations were performed with a supply frequency equal to $f_{s}=50 \mathrm{~Hz}$ and nominal speed equal to $\Omega_{m}=1425 \mathrm{rpm}$. The stator current signals have been recorded during 1 second with a $1 \mathrm{kHz}$ sampling rate. 


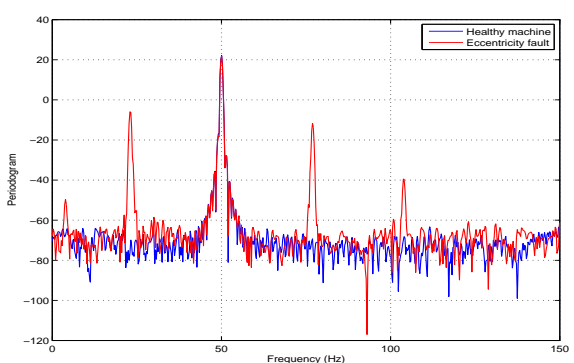

(a) Periodogram (Hanning Window).

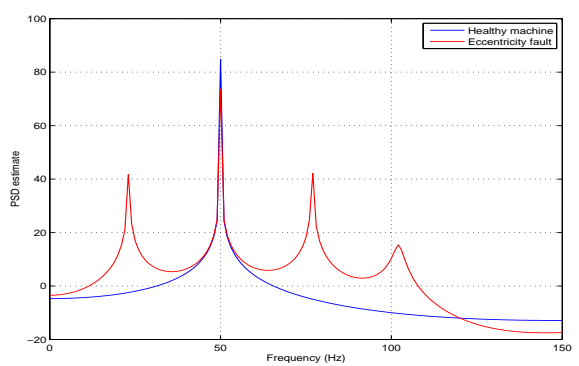

(b) MUSIC pseudospectrum. ( $\mathrm{L}=16)$.

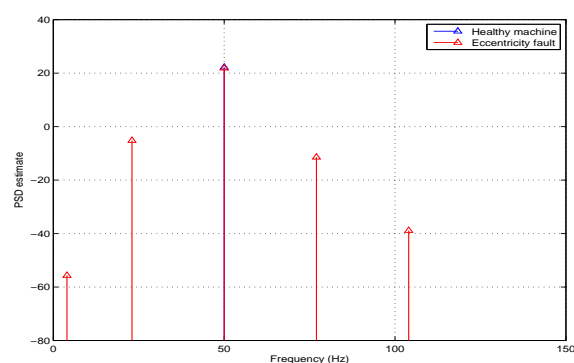

(c) Proposed Approach.

Fig. 8. Stator current PSD for a faulty motor (Mixed eccentricity).

Table 2 . Eccentricity fault simulation results.

(a) Exact PSD estimator.

\begin{tabular}{|c||c|c|c|}
\hline State & $\widehat{L}$ & $\begin{array}{c}\widehat{f}_{c} \\
(\mathrm{~Hz})\end{array}$ & $\begin{array}{c}\mathcal{C} \\
\left(\times 10^{-3}\right)\end{array}$ \\
\hline \hline Healthy & 0 & 0 & 0 \\
\hline Static & 1 & 24.46 & 1.1 \\
eccentricity & & & \\
\hline Dynamic & 1 & 48.87 & 5.3 \\
eccentricity & & & \\
\hline Mixed & 2 & 24.43 & \\
\hline
\end{tabular}

(b) Approximated PSD estimator.

\begin{tabular}{|c||c|c|c|}
\hline State & $\widehat{L}$ & $\begin{array}{c}\widehat{f}_{c} \\
(\mathrm{~Hz})\end{array}$ & $\begin{array}{c}\mathcal{C} \\
\left(\times 10^{-3}\right)\end{array}$ \\
\hline \hline Healthy & 4 & 10 & 0.94 \\
\hline Static & 2 & 12.3 & 1.5 \\
eccentricity & & & \\
\hline Dynamic & 2 & 12.22 & 5.5 \\
eccentricity & & & \\
\hline Mixed & 4 & 12.21 & 8.4 \\
\hline
\end{tabular}

\subsubsection{Eccentricity fault detection results}

The PSD of the stator current using the periodogram, MUSIC algorithm, and the proposed approach are depicted in Fig. 8 for the same simulation parameters as the ones used in Fig. 1 .

The algorithm shown in Fig. 6 is used to extract a fault detection criterion. The eccentricity fault characteristic frequency is used, i.e. $f_{k}(\Omega)=f_{s} \pm k f_{c}$ where $f_{c}=\left(\frac{1-s}{p}\right) f_{s}$. The grid search algorithm has been implemented using a fine search: $f_{c}$ ranges from $0 \mathrm{~Hz}$ to $100 \mathrm{~Hz}$ with a step size of $0.01 \mathrm{~Hz}$. Table 2 summarizes the simulation results. This table presents the estimated fault frequency $f_{c}$, the sidebands number $L$, and the fault detection criterion $\mathcal{C}$. The fault detection criterion $\mathcal{C}$ is computed using (28).

The analysis of Table 2 allows concluding that the two proposed approaches permit to detect the eccentricity fault. Indeed in presence of eccentricity faults, the fault criterion increases significantly. Therefore, a simple threshold-based decision can distinguish between the healthy and the faulty cases. However, it is obvious that the exact method gives more reliable results since the criterion is null for healthy case which confirms the theoretical study. The FFT-based approach tends to over-estimate $L$ which leads to values of $f_{c}$ equal to half the true value given by the exact method. The last ascertainment is due to sidelobes (due to sampling) present in the signal FFT which are interpreted as sidebands (characteristic fault frequency). 


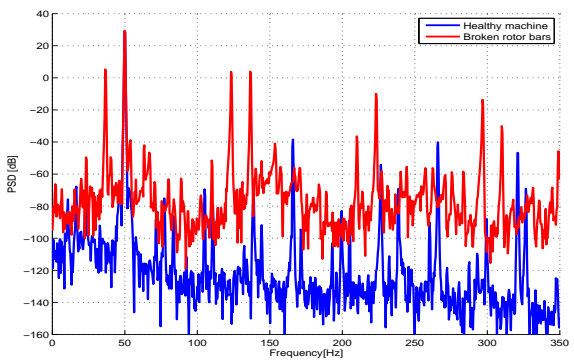

(a) Periodogram (Hanning window).

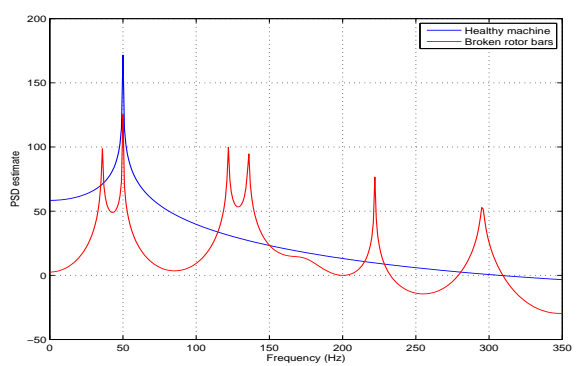

(b) MUSIC pseudospectrum. ( $\mathrm{L}=16)$.

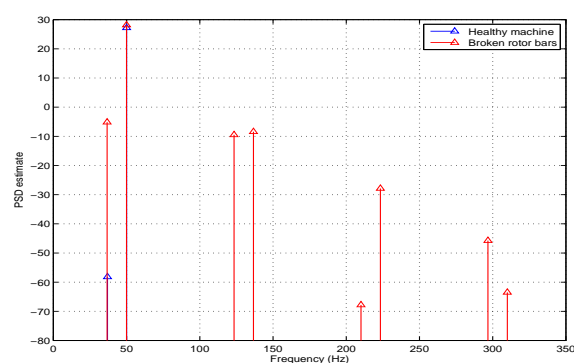

(c) Proposed Approach.

Fig. 9 . PSD of the stator current with 3 broken rotor bars.

\subsubsection{Broken rotor bars fault detection results}

Broken rotor bar is one of the electrical faults that is difficult to detect since the squirrel cage current can not be acquired. The PSD of the stator current using the periodogram, MUSIC algorithm, and the proposed approach are depicted in Fig. 9 for the same simulation parameters as the ones used in Fig. 1.

The broken rotor bars characteristic frequency is used in the signal model i.e. $f_{k}(\Omega)=f_{k}\left(f_{s}, s\right)=$ $f_{s}\left[k\left(\frac{1-s}{p}\right) \pm s\right]$. Computer simulations have been performed for assessment of operating features of the proposed fault detection scheme.

Table 3 . Broken rotor bars simulation results.

(a) Exact PSD estimator.

\begin{tabular}{|c||c|c|c|c|}
\hline State & $\widehat{L}$ & $\widehat{k / p}$ & $\widehat{s}$ & $\mathcal{C}$ \\
$(\%)$ & $\left(\times 10^{-3}\right)$ \\
\hline \hline Healthy & 0 & 0 & 0 & 0 \\
\hline 1 broken bar & 3 & $1,3,5$ & 5.8 & 4.6 \\
\hline 2 broken bars & 4 & $1,3,5,7$ & 6.2 & 24.4 \\
\hline 3 broken bars & 5 & $1,3,5,7,11$ & 6.6 & 49.7 \\
\hline
\end{tabular}

(b) Approximated PSD estimator.

\begin{tabular}{|c||c|c|c|c|}
\hline State & $\widehat{L}$ & $\widehat{k / p}$ & $\widehat{s}$ & $\mathcal{C}$ \\
$(\%)$ & $\left(\times 10^{-3}\right)$ \\
\hline \hline Healthy & 1 & 1 & 3.13 & 1.8 \\
\hline 1 broken bar & 3 & $1,3,5$ & 5.85 & 4.3 \\
\hline 2 broken bars & 4 & $1,3,5,7$ & 6.16 & 22.6 \\
\hline 3 broken bars & 5 & $1,3,5,7,11$ & 6.57 & 45.2 \\
\hline
\end{tabular}

Table 3 gives simulation results for 1 to 3 broken rotor bars for both the exact and FFT-based techniques. The broken bars are adjacent. The criterion has been evaluated for different fault degrees. It can be noticed that the fault criterion varies in proportion to the number of broken rotor bars. The same conclusions can be drawn from the broken rotor bars results. It is worthy to notice that in the exact approach case, the estimation of $\frac{k}{p}$ leads to informations about faults presence. This is not the case for FFT-based approach since the algorithm interprets sidelobes as sidebands which may lead to false alarm.

\subsection{Experimental Results}

This section reports on the performance of the proposed approaches. First, the test rig is presented, then the proposed techniques was applied off-line using Matlab for bearing faults detection in a conventional induction machine. 


\begin{tabular}{|c||c|c|}
\hline Bearing fault & Fault related frequency & Theoretical values $(\mathrm{Hz})$ \\
\hline \hline Cage defect & $f_{c}=\frac{f_{r}}{2}\left(1-\frac{d}{D} \cos (\alpha)\right)$ & {$[14.4,27.077]$} \\
\hline Ball defect & $f_{b d}=\frac{D}{d} f_{r}\left(1-\frac{d^{2}}{D^{2}} \cos ^{2}(\alpha)\right)$ & {$[105.5,119.47]$} \\
\hline Inner raceway & $f_{i d}=\frac{n f_{r}}{2}\left(1+\frac{d}{D} \cos (\alpha)\right)$ & {$[154.04,255.1]$} \\
\hline Outer raceway & $f_{o d}=\frac{n f_{r}}{2}\left(1-\frac{d}{D} \cos (\alpha)\right)$ & {$[115.5,216.6]$} \\
\hline
\end{tabular}

Table 4 . Theoretical values of bearing faults frequencies

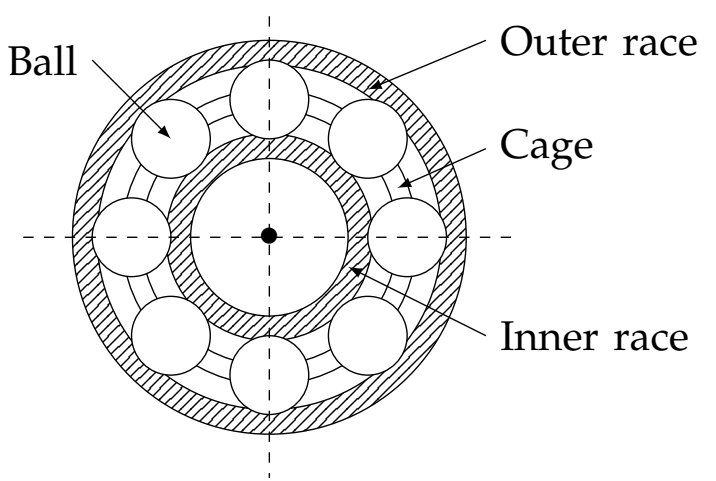

(a) Geometry of a rolling-element bearing.

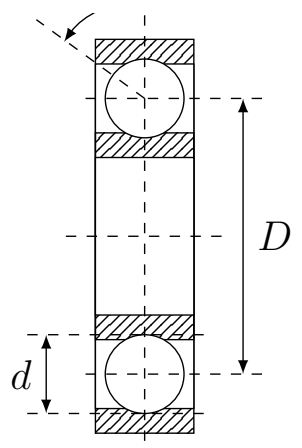

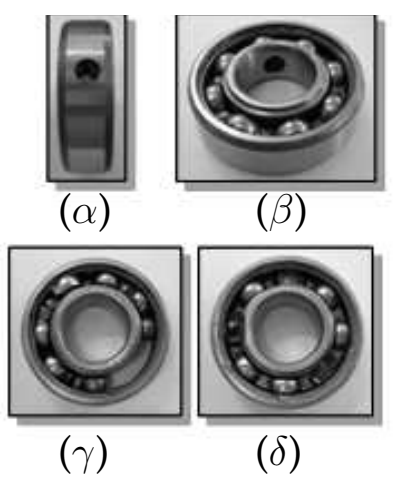

(b) Artificially deteriorated bearing.

Fig. 10 . Bearing structure with main dimensions $((\alpha)$ outer race deterioration, $(\beta)$ inner race deterioration, $(\gamma)$ cage deterioration, $\delta$ ball deterioration).

\subsubsection{Test rig}

A conventional $0.75 \mathrm{~kW}$ induction machine drive test rig is used in order to test the proposed parametric spectral estimation fault detection approach (Fig. 11). The rated data of the used induction machine are given in Appendix F.

The test rig mechanical part is composed by a synchronous and an induction machine. The induction machine is fed by the synchronous generator in order to eliminate time-harmonics. Indeed, this will automatically eliminate supply harmonics and therefore allow focusing only on bearing faults effect on the stator current.

The induction machine has two 6204.2 ZR type bearings (single row and deep groove ball bearings) with the following parameters: outside diameter is $47 \mathrm{~mm}$, inside diameter is $20 \mathrm{~mm}$, and pitch diameter $\mathrm{D}$ is $31.85 \mathrm{~mm}$. A bearing has $n=8$ balls with an approximate diameter $\mathrm{d}$ of $12 \mathrm{~mm}$ and a contact angle of $\alpha=0^{\circ}$ (Fig. 10). Based on these dimensions, the theoretical values of the different bearing fault frequencies are given in Table 4 .

Bearing failure is one of the foremost causes of breakdowns in rotating machinery, resulting in costly downtime (Fig. 3b) [39]. One of the key issues in bearing prognostics is to detect the defect at its incipient stage and alert the operator before it develops into catastrophic failure. Hence, bearing faults are obtained by simply drilling holes in different parts [51].

In order to study the load influence, the induction machine was operated with various load levels ranging from $0 \mathrm{~W}$ to $400 \mathrm{~W}$.

The measured quantities for off-line bearing fault detection were the line-currents. For all the experiments, the stator fundamental frequency was equal to $f_{s}=50 \mathrm{~Hz}$. All the signals were acquired at a $10 \mathrm{kHz}$ sampling frequency by a data acquisition card and processed using Matlab-simulink ${ }^{\circledR}$. As the information relative to the bearing faults is mostly contained in the low frequency content, these signals were down-sampled at a $600 \mathrm{~Hz}$ sampling rate.

\subsubsection{Fault detection results}

In presence of bearing faults, it has been shown in [40] that the fault characteristic frequencies are given by: $f_{k}(\Omega)=\left|f_{s} \pm k f_{c}\right|(k \in \mathbb{Z})$. In [41], it has been demonstrated that depending on 


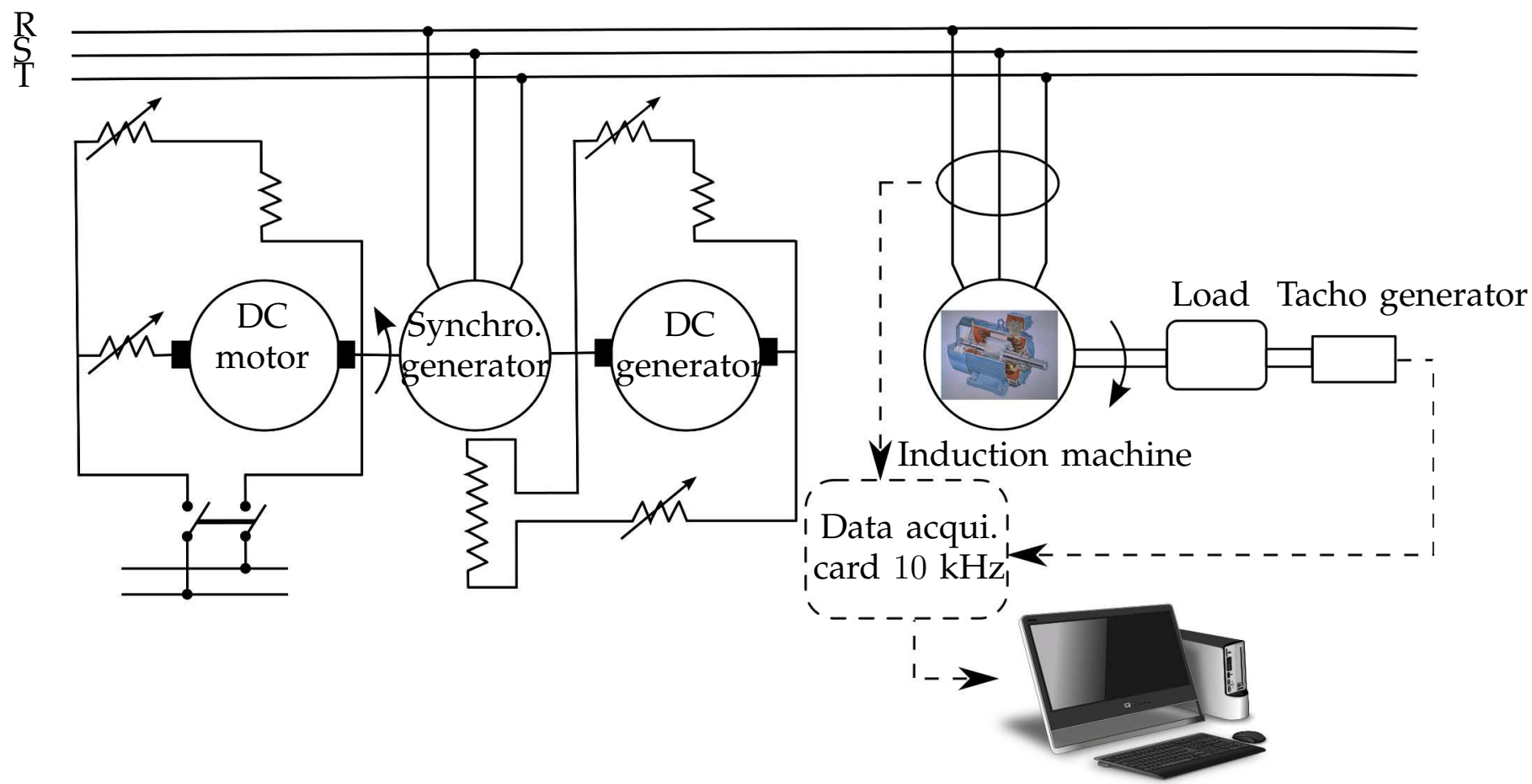

Fault detection algorithm

Fig. 11 . Test rig scheme.

the bearing fault effect on the induction machine behavior (eccentricity or torque variations) the bearing fault-related frequencies in the stator current spectrum is different. In this section, we consider only the case where the localized single-point bearing defects leads to the torque variations. Hence, the model in [40] has been considered.

The algorithm in Fig. 6 is again used to extract a fault detection criterion. Similarly to the simulation configuration, the number $L$ has been estimated in order to decide whether the induction machine is operating with healthy bearings or damaged once. If $L=0$ then the bearings are safe, otherwise the bearing is damaged and criterion in $(28)$ is computed in order to measure the fault severity and then take decision. Preliminary tests have shown that most of the characteristic fault frequencies are greater than $f_{s}=50 \mathrm{~Hz}$ which means that most of the frequency components related to fault are located at the right-side of the supply frequency $f_{s}$ due to the absolute value of the frequencies introduced by faults (Table 11). Therefore, the proposed approach has been used to extract these right-side components. This simplification is not equivalent to minimization of time-harmonics in power supply since these frequencies are different from multiples of the fundamental frequency $f_{s}=50 \mathrm{~Hz}$.

Experimental results are reported in Figs. $12 \mathrm{a}$ and $12 \mathrm{~b}$ for the exact and approximate approaches, respectively. These figures display the criterion $\mathcal{C}$ for healthy and faulty machines with various load levels.

For the exact algorithm, in the case of healthy machine, it is obvious that $L=0$ which implies that the criterion is equal to 0. From this bar chart, it could be observed that the proposed criterion significantly increases for each faulty machine, regardless of the fault type and load level. Therefore, a simple estimation of $L$ gives an indication of the existence of fault. However, In the case of approximated approach based on the FFT, the estimation of $L$ can not be a reliable way to distinguish faulty from healthy case since $L$ is different from 0 even if the machine is operating correctly. That's why, the criterion computation is mandatory and threshold-based 


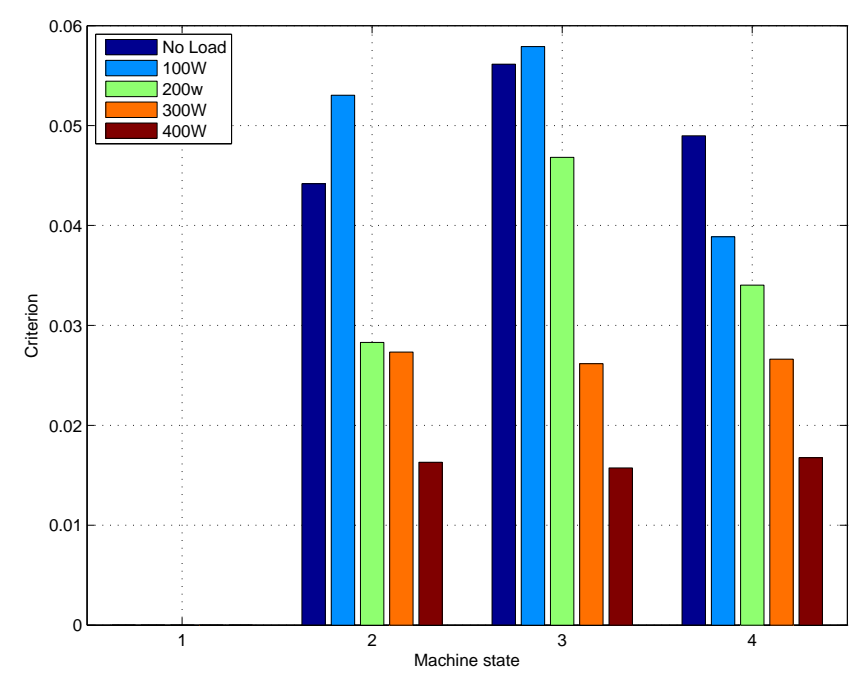

(a) Exact PSD estimator: values of the fault detection criterion $\mathcal{C}$ for 1- Healthy case 2- Inner raceway fault 3- Cage fault 4Ball fault.

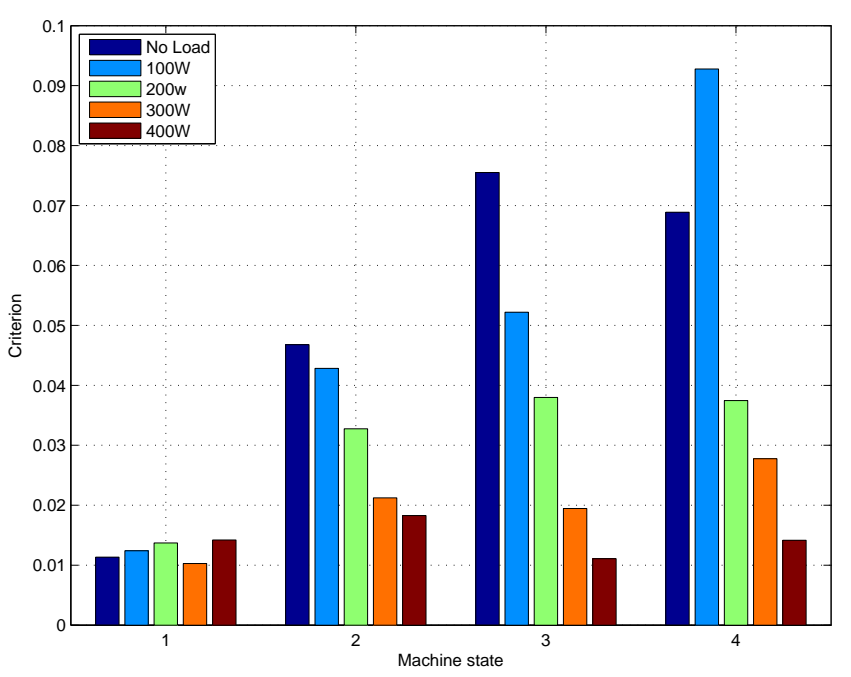

(b) Approximate PSD estimator: values of the fault detection criterion $\mathcal{C}$ for 1 - Healthy case 2 - Inner raceway fault 3- Cage fault 4- Ball fault.

Fig. 12 . Performance of the proposed approaches on experimental data.

fault detector must be defined in order to distinguish between healthy and faulty machines.

By comparing the two techniques, we can note that the exact approach is more reliable than the approximated method which is less time consuming. However, it must be emphasized that the approximate approach has practical advantages since it is based on the DFT (easiness of implementation, fast computation with FFT). The two figures also show that the criterion $\mathcal{C}$ decreases with the load level; there is only one exception to this rule for the healthy machine in the case of approximated algorithm. This could be explained by the fact that the load tends to hide the faults effect on the stator current [52]. This is clearly illustrated in Fig. $12 \mathrm{~b}$ when the load is equal to $400 \mathrm{~W}$. This results obviously confirms the effectiveness of the proposed technique over the FFT-based one.

The proposed technique allows detecting several induction machine faults. In order to characterize the fault (defected component, fault severity, etc.) another step is required which has not been addressed within this paper. However, the proposed technique may be used as an input for a fault classifier since it allows the extraction of the fault frequency signatures. Once the fault sensitive frequencies are extracted, the signatures given in the literature may be used to discriminate several faults.

\section{CONCLUSIONS}

This paper has proposed a statistical-based approach for fault detection in induction machines. The proposed approach is composed of two steps: a) the estimation of the PSD with a new parametric technique, and $b$ ) the computation of a fault detection criterion.

The proposed PSD estimator has been computed using the maximum likelihood estimation approach. As opposed to non-parametric PSD estimators, the proposed technique exploits the fault frequency signatures in order to improve the performance of the fault detection criterion. As a result, the proposed estimator has better frequency-resolution and frequency-accuracy than other techniques such as the periodogram. When the number of samples goes to infinity, it has also been demonstrated that the proposed PSD estimator can be efficiently implemented using the Discrete Fourier Transform. However, this approximated method does not perform as well as the exact method for short signals. Concerning the fault detection criterion, we have proposed 
a criterion based on the amplitude of the fault-related frequencies. This criterion is theoretically equal to zero for healthy machine and increases for faulty once.

The proposed approach was successfully tested on simulations with eccentricity and broken rotor bars faults and experimental test rig with various bearing faults and load conditions. Simulation and experimental results have corroborated the efficiency of the proposed method, regardless of the fault type in contrary to the FFT-based approach. Furthermore, these results have suggested that the estimation of $L$ is very interesting since it allows to make a direct and fast first idea about the machine state.

Further investigations are required in order to study the effect of the induction machine faults over the time- and space-harmonics of the stator current. Furthermore, the impact of these harmonics over the reliability of the proposed technique should be highlighted.

\section{APPENDIX A}

\section{ESTIMATION OF $\mathbf{V}$}

By expanding (9), we obtain:

$$
\begin{aligned}
\mathcal{L}(\mathbf{x} ; \mathbf{v}, \Omega) & =(\mathbf{x}-\mathbf{A}(\Omega) \mathbf{v})^{T}(\mathbf{x}-\mathbf{A}(\Omega) \mathbf{v}) \\
& =\left(\mathbf{x}^{T}-\mathbf{v}^{T} \mathbf{A}^{T}(\Omega)\right)(\mathbf{x}-\mathbf{A}(\Omega) \mathbf{v}) \\
& =\mathbf{x}^{T} \mathbf{x}-2 \mathbf{v}^{T} \mathbf{A}^{T}(\Omega) \mathbf{x}+\mathbf{v}^{T} \mathbf{A}^{T}(\Omega) \mathbf{A}(\Omega) \mathbf{v}
\end{aligned}
$$

The derivative of $\mathcal{L}(\mathbf{x} ; \mathbf{v}, \Omega)$ with respect to $\mathbf{v}$ is equal to (see reference [53]):

$$
\begin{aligned}
\frac{\partial \mathcal{L}(\mathbf{x} ; \mathbf{v}, \Omega)}{\partial \mathbf{v}} & =-2 \mathbf{A}^{T}(\Omega) \mathbf{x}+2 \mathbf{A}^{T}(\Omega) \mathbf{A}(\Omega) \mathbf{v} \\
& =-2 \mathbf{A}^{T}(\Omega)(\mathbf{x}-\mathbf{A}(\Omega) \mathbf{v})
\end{aligned}
$$

Setting the above derivative to zero, we obtain the ML estimator of $\mathbf{v}$, which is denoted $\widehat{\mathbf{v}}$ :

$$
\left.\frac{\partial \mathcal{L}(\mathbf{x} ; \mathbf{v}, \Omega)}{\partial \mathbf{v}}\right|_{\mathbf{v}=\widehat{\mathbf{v}}}=0 \Rightarrow \mathbf{x}=\mathbf{A}(\Omega) \widehat{\mathbf{v}}
$$

Finally, we obtain the following ML estimator of $\mathbf{v}$ :

$$
\widehat{\mathbf{v}}=\mathbf{A}^{\dagger}(\Omega) \mathbf{x}
$$

where $\mathbf{A}^{\dagger}(\Omega)$ is the pseudo-inverse of $\mathbf{A}(\Omega)$ i.e.

$$
\mathbf{A}^{\dagger}(\Omega)=\left(\mathbf{A}^{T}(\Omega) \mathbf{A}(\Omega)\right)^{-1} \mathbf{A}^{T}(\Omega)
$$

\section{APPENDIX B}

\section{ESTIMATION OF $\Omega$}

The ML estimate of $f_{k}(\Omega)$ is obtained by minimizing $\mathcal{L}(\mathbf{x} ; \widehat{\mathbf{v}}, \Omega)$ with respect to $\Omega$. By replacing $\mathbf{v}$ by $\widehat{\mathbf{v}}$ in $(9)$, we obtain:

$$
\begin{aligned}
\mathcal{L}(\mathbf{x} ; \widehat{\mathbf{v}}, \Omega) & =(\mathbf{x}-\mathbf{A}(\Omega) \widehat{\mathbf{v}})^{T}(\mathbf{x}-\mathbf{A}(\Omega) \widehat{\mathbf{v}}) \\
& =\left(\mathbf{x}-\mathbf{A}(\Omega) \mathbf{A}^{\dagger}(\Omega) \mathbf{x}\right)^{T}\left(\mathbf{x}-\mathbf{A}(\Omega) \mathbf{A}^{\dagger}(\Omega) \mathbf{x}\right) \\
& =\mathbf{x}^{T}\left(\mathbf{I}_{N}-\mathbf{A}(\Omega) \mathbf{A}^{\dagger}(\Omega)\right) \mathbf{x}
\end{aligned}
$$


where the last equality has been obtained using (35). Neglecting the terms that do not depend on $\Omega$, it can be shown that the ML estimate of $\Omega$ is given by

$$
\{\widehat{\Omega}\}=\arg \max _{\Omega} \mathcal{J}(\Omega)
$$

where:

$$
\mathcal{J}(\Omega)=\mathbf{x}^{T} \mathbf{A}(\Omega) \mathbf{A}^{\dagger}(\Omega) \mathbf{x}
$$

\section{APPENDIX C}

\section{MODEL ORDER ESTIMATION}

Departing from 14 we have

$$
\begin{aligned}
\mathcal{C}_{F} & =-2 \log p\left(\mathbf{x}, \widehat{\mathbf{v}}, \widehat{\sigma}^{2}, \Omega, L\right)+c(g, N) \\
& =2 \log \left(\left(2 \pi \widehat{\sigma}^{2}\right)^{\frac{N}{2}}\right)-\frac{1}{\widehat{\sigma}^{2}}\left[(\mathbf{x}-\mathbf{A}(\Omega) \widehat{\mathbf{v}})^{T}(\mathbf{x}-\mathbf{A}(\Omega) \widehat{\mathbf{v}})\right]+c(g, N) \\
& =N \log \left(\left(2 \pi \widehat{\sigma}^{2}\right)\right)-\frac{1}{\widehat{\sigma}^{2}}\left[(\mathbf{x}-\mathbf{A}(\Omega) \widehat{\mathbf{v}})^{T}(\mathbf{x}-\mathbf{A}(\Omega) \widehat{\mathbf{v}})\right]+c(g, N) \\
& =\log \left(\left(2 \pi \widehat{\sigma}^{2}\right)\right)-\frac{1}{\widehat{\sigma}^{2}}\left[\frac{(\mathbf{x}-\mathbf{A}(\Omega) \widehat{\mathbf{v}})^{T}(\mathbf{x}-\mathbf{A}(\Omega) \widehat{\mathbf{v}})}{N}\right]+\frac{c(g, N)}{N}
\end{aligned}
$$

Using (15) the cost function is equivalent to

$$
\mathcal{C}_{F 1}=\log \left(\left(2 \pi \widehat{\sigma}^{2}\right)\right)+\frac{c(g, N)}{N}
$$

Since the exp function is strictly increasing, applying the exp on (43) gives

$$
\mathcal{C}_{F 2}=\left(2 \pi \widehat{\sigma}^{2}\right) \times \exp \left(\frac{c(g, N)}{N}\right)
$$

Replacing (15) in (44) gives the equation given in (17). 


\section{APPENDIX D}

\section{LINK WITH FFT PROOF}

$$
\begin{aligned}
& \mathcal{J}_{a}(\Omega)=\frac{2}{N} \mathbf{x}^{T} \mathbf{A}(\Omega) \mathbf{A}^{T}(\Omega) \mathbf{x} \\
& =\frac{2}{N}\left\|\mathbf{A}^{T} \mathbf{x}\right\|_{F} \\
& =\frac{2}{N}\left\|\left[\mathbf{z}_{-L} \ldots \mathbf{z}_{L}, \mathbf{y}_{-L} \ldots \mathbf{y}_{L}\right]^{T}[x[0] \quad x[1] \quad \ldots \quad x[N-1]]^{T}\right\|_{F} \\
& =\frac{2}{N}\left\|\left[\begin{array}{c}
\sum_{n=0}^{N-1} x[n] \cos \left(2 \pi f_{-L}(\Omega) \times \frac{n}{F_{s}}\right) \\
\vdots \\
\sum_{n=0}^{N-1} x[n] \cos \left(2 \pi f_{L}(\Omega) \times \frac{n}{F_{s}}\right) \\
\sum_{n=0}^{N-1} x[n] \sin \left(2 \pi f_{-L}(\Omega) \times \frac{n}{F_{s}}\right) \\
\vdots \\
\sum_{n=0}^{N-1} x[n] \sin \left(2 \pi f_{L}(\Omega) \times \frac{n}{F_{s}}\right)
\end{array}\right]\right\|_{F} \\
& =\frac{2}{N} \sum_{k=-L}^{L}\left[\sum_{n=0}^{N-1} x[n] \cos \left(2 \pi f_{k}(\Omega) \frac{n}{F_{s}}\right)\right]^{2}+\left[\sum_{n=0}^{N-1} x[n] \sin \left(2 \pi f_{k}(\Omega) \frac{n}{F_{s}}\right)\right]^{2} \\
& =\frac{2}{N} \sum_{k=-L}^{L}\left|\sum_{n=0}^{N-1} x[n] e^{-j 2 \pi f_{k}(\Omega) \frac{n}{F_{s}}}\right|^{2}
\end{aligned}
$$

\section{APPENDIX E}

By using (4), we obtain:

$$
\begin{aligned}
\mathbf{v}^{T} \mathbf{v} & =\sum_{k=-L}^{L} a_{k}^{2} \cos ^{2}\left(\phi_{k}\right)+\sum_{k=-L}^{L} a_{k}^{2} \sin ^{2}\left(\phi_{k}\right) \\
& =\sum_{k=-L}^{L} a_{k}^{2}
\end{aligned}
$$

By using the structure of $\mathbf{M}$, we also get:

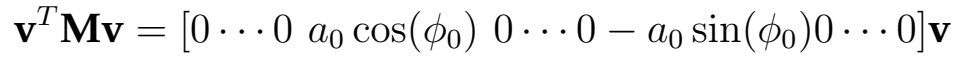

$$
\begin{aligned}
& =a_{0}^{2} \cos ^{2}\left(\phi_{0}\right)+a_{0}^{2} \sin ^{2}\left(\phi_{0}\right) \\
& =a_{0}^{2}
\end{aligned}
$$

These two equations lead to the following result:

$$
\begin{aligned}
\frac{\mathbf{v}^{T} \mathbf{v}}{\mathbf{v}^{T} \mathbf{M v}}-1 & =\left(\sum_{k=-L}^{L} \frac{a_{k}^{2}}{a_{0}^{2}}\right)-\frac{a_{0}^{2}}{a_{0}^{2}} \\
& =\sum_{k=-L, k \neq 0}^{L}\left(\frac{a_{k}^{2}}{a_{0}^{2}}\right)=\mathcal{C}
\end{aligned}
$$




\section{APPENDIX F}

RATED DATA OF THE TESTED INDUCTION MACHINE

$0.75 \mathrm{~kW}, 50 \mathrm{~Hz}, 220 / 380 \mathrm{~V}, 3.4 / 1.95 \mathrm{~A}, 2780 \mathrm{rpm}, p=1$

\section{REFERENCES}

[1] S. Nandi, H. A. Toliyat, and X. Li, "Condition monitoring and fault diagnosis of electrical motors - a review," IEEE Transactions on Energy Conversion, vol. 20, no. 4, pp. 719-729, December 2005.

[2] A. Garcia-Perez, R. de Jesus Romero-Troncoso, E. Cabal-Yepez, and R. Osornio-Rios, "The application of high-resolution spectral analysis for identifying multiple combined faults in induction motors," IEEE Transactions on Industrial Electronics, vol. 58, no. 5, pp. 2002-2010, May 2011.

[3] M. Seera, C. P. Lim, D. Ishak, and H. Singh, "Fault detection and diagnosis of induction motors using motor current signature analysis and a hybrid fmm-cart model," IEEE Transactions on Neural Networks and Learning Systems, vol. 23, no. 1, pp. 97-108, January 2012.

[4] V. Choqueuse, M. E. H. Benbouzid, Y. Amirat, and S. Turri, "Diagnosis of three-phase electrical machines using multidimensional demodulation techniques," IEEE Transactions on Industrial Electronics, vol. 59, no. 4, pp. 2014-2023, April 2011.

[5] X. Gong and W. Qiao, "Imbalance fault detection of direct-drive wind turbines using generator current signals," IEEE Trans. Energy Conversion, vol. 27, no. 2, pp. 468-476, June 2012.

[6] B. Trajin, "Analyse et traitement de grandeurs électriques pour la détection et le diagnostic de défauts mécaniques dans les entraînements asynchrones. application à la surveillance des roulements à billes," Ph.D. dissertation, Institut National Polytechnique de Toulouse-INPT, 2009.

[7] M. E. H. Benbouzid and G. B. Kliman, "What stator current processing based technique to use for induction motor rotor faults diagnosis?" IEEE Transactions on Energy Conversion, vol. 18, no. 2, pp. 238-244, June 2003.

[8] P. J. Tavner and J. Penman, Condition monitoring of electrical machines. Research Studies Press Letchworth, 1987, vol. 1.

[9] J. Cameron, W. Thomson, and A. Dow, "Vibration and current monitoring for detecting airgap eccentricity in large induction motors," Electric Power Applications, IEE Proceedings B, vol. 133, no. 3, pp. 155-163, May 1986.

[10] I. Mitchel, "Study of time and frequency domain analysis techniques for rotor cage fault detection," Ph.D. dissertation, Thesis Gordons Institute of Technology Aberdeen, Mai 1986.

[11] M. E. H. Benbouzid, "A review of induction motors signature analysis as a medium for faults detection," IEEE Transactions Industrial Electronics, vol. 47, no. 5, pp. 984-993, October 2000.

[12] A. Bellini, F. Filippetti, C. Tassoni, and G. A. Capolino, "Advances in Diagnostic Techniques for Induction Machines," IEEE Transactions on Industrial Electronics, vol. 55, no. 12, pp. 4109-4126, Dec. 2008.

[13] E. H. El Bouchikhi, V. Choqueuse, M. E. H. Benbouzid, J. Charpentier, and G. Barakat, "A comparative study of timefrequency representations for fault detection in wind turbine," in Proceedings of the 2011 IEEE IECON, Melbourne (Australia), Nov. 2011, pp. 3584-3589.

[14] E. H. El Bouchikhi, V. Choqueuse, and M. E. H. Benbouzid, "Current frequency spectral subtraction and its contribution to induction machines' bearings condition monitoring," IEEE Transactions on Energy Conversion, vol. 28, no. 1, pp. 135-144, March 2013.

[15] P. Stoica and R. L. Moses, Introduction to Spectral Analysis. Prentice-Hall, New Jersey, 1997.

[16] H. Renders, J. Schoukens, and G. Vilain, "High-accuracy spectrum analysis of sampled discrete frequency signals by analytical leakage compensation," IEEE Trans. Instrum. Meas, vol. 33, no. 4, pp. 287-292, 1984.

[17] D. R. A. McMahon and R. F. Barrett, "An efficient method for the estimation of the frequency of a single tone in noise from the phases of discrete fourier transforms," IEEE Transactions on Signal Processing, vol. 11, pp. 169-177, 1986.

[18] B. G. Quinn, "Estimation of frequency, amplitude, and phase from the dft of a time series," IEEE Transactions on Signal Processing, vol. 45, no. 3, pp. 814-817, 1997.

[19] — , "Estimating frequency by interpolation using fourier coefficients," Signal Processing, IEEE Transactions on, vol. 42, no. 5, pp. 1264-1268, 1994.

[20] J. Schoukens, R. Pintelon, and H. Van Hamme, "The interpolated fast fourier transform: a comparative study," IEEE Transactions on Instrumentation and Measurement, vol. 41, no. 2, pp. 226-232, 1992.

[21] F. J. Harris, "On the use of windows for harmonic analysis with the discrete fourier transform," Proceedings of the IEEE, vol. 66, no. 1, pp. 51-83, 1978.

[22] R. B. Randall, Vibration-based condition monitoring: industrial, aerospace and automotive applications. John Wiley \& Sons, 2011.

[23] A. Oppenheim, R. Schafer, and W. Padgett, Discrete-Time Signal Processing, 3rd ed. Prentice Hall, 2009.

[24] G. Didier, E. Ternisien, O. Caspary, and H. Razik, "fault detection of broken rotor bars in induction motor using a global fault index," IEEE Transactions on Industry Applications, vol. 42, no. 1, pp. 79-88, Jan./Feb. 2006.

[25] M. E. H. Benbouzid, M. Vieira, and C. Theys, "Induction motors' faults detection and localization using stator current advanced signal processing techniques," IEEE Transactions on Power Electronics, vol. 14, no. 1, pp. 14-22, January 1999.

[26] A. Bellini, A. Yazidi, F. Filippetti, C. Rossi, and G. Capolino, “High frequency resolution techniques for rotor fault detection of induction machines," IEEE Transactions on Industrial Electronics, vol. 55, no. 12, pp. 4200-4209, Dec. 2008. 
[27] R. Puche-Panadero, M. Pineda-Sanchez, M. Riera-Guasp, J. Roger-Folch, E. Hurtado-Pearez, and J. Perez-Cruz, "Improved resolution of the mcsa method via hilbert transform, enabling the diagnosis of rotor asymmetries at very low slip," IEEE Trans. Energy Conversion, vol. 24, no. 1, pp. 52-59, March 2009.

[28] Z. Leonowicz, T. Lobos, and J. Rezmer, "Advanced spectrum estimation methods for signal analysis in power electronics," IEEE Transactions on Industrial Electronics, vol. 50, no. 3, pp. 514-519, June 2003.

[29] J. Stack, T. Habetler, and R. Harley, "Bearing fault detection via autoregressive stator current modeling," IEEE Transactions on Industry Applications, vol. 40, no. 3, pp. 740-747, May/June 2004.

[30] E. H. El Bouchikhi, V. Choqueuse, and M. E. H. Benbouzid, "Induction machine fault detection enhancement using a stator current high resolution spectrum," in Proceedings of the 2012 IEEE IECON, Montral (Canada), Octo. 2012, pp. 3893-3898.

[31] A. Bracale, G. Carpinelli, L. Piegari, and P. Tricoli, "A high resolution method for on line diagnosis of induction motors faults," in Proceedings of IEEE Power Tech., Lausanne, Suisse, July 2007, pp. 994-998.

[32] F. Cupertino, E. de Vanna, L. Salvatore, and S. Stasi, "Analysis techniques for detection of im broken rotor bars after supply disconnection," IEEE Transactions on Industry Applications, vol. 40, no. 2, pp. 526-533, March/April 2004.

[33] S. H. Kia, H. Henao, and G. A. Capolino, "A high-resolution frequency estimation method for three-phase induction machine fault detection," IEEE Transactions on Industrial Electronics, vol. 54, no. 4, pp. 2305-2314, August 2007.

[34] A. Bellini, G. Franceschini, and C. Tassoni, "Monitoring of induction machines by maximum covariance method for frequency tracking," IEEE Transactions on Industry Applications, vol. 42, no. 1, pp. 69-78, Jan./Feb. 2006.

[35] B. Yazici and G. B. Kliman, "An adaptive statistical time-frequency method for detection of broken bars and bearing faults in motors using stator current," IEEE Transactions on Industry Applications, vol. 35, no. 2, pp. 442-452, Mar./Apr. 1999.

[36] M. Blodt, M. Chabert, J. Regnier, and J. Faucher, "Mechanical load fault detection in induction motors by stator current time-frequency analysis," IEEE Transactions on Industry Applications, vol. 42, no. 6, pp. 1454-1463, 2006.

[37] E. H. El Bouchikhi, V. Choqueuse, and M. E. H. Benbouzid, "A parametric spectral estimator for faults detection in induction machines," in Proceedings of the 2013 IEEE IECON, Vienna (Austria), Nov. 2013, pp. 7356-7361.

[38] P. Zhang, Y. Du, T. Habetler, and B. Lu, "A survey of condition monitoring and protection methods for medium-voltage induction motors," IEEE Transactions on Industry Applications, vol. 47, no. 1, pp. 34-46, January/February 2011.

[39] A. H. Bonnett and C. Yung, "Increased efficiency versus increased reliability," IEEE Industry Applications Magazine, vol. 14, no. 1, Jan./Feb. 2008.

[40] R. Schoen, T. Habetler, F. Kamran, and R. Bartheld, "Motor bearing damage detection using stator current monitoring," IEEE Transactions on Industry Applications, vol. 31, no. 5, pp. 1274-1279, November/December 1995.

[41] M. Blodt, P. Granjon, B. Raison, and G. Rostaing, "Models for bearing damage detection in induction motors using stator current monitoring," IEEE Transactions on Industrial Electronics, vol. 55, no. 4, pp. 1813-1822, April 2008.

[42] M. Blödt, P. Granjon, B. Raison, J. Regnier et al., "Mechanical fault detection in induction motor drives through stator current monitoring-theory and application examples," Fault Detection, Wei Zhang (Ed.), pp. 451-488, 2010.

[43] S. Kay, Fundamentals of Statistical Signal Processing: Estimation Theory. Prentice-Hall signal processing series, 1993, 17th Printing.

[44] H. Li, P. Stoica, and J. Li, "Computationally efficient parameter estimation for harmonic sinusoidal signals," Signal Processing, vol. 80, pp. 1937-1944, September 2000.

[45] Y. Bresler, "Exact maximum likelihood parameter estimation superimposed exponential signals in noise," IEEE Transactions on Acoustics, Speech, and Signal Processing, vol. 1, no. 5, pp. 1081-1089, October 1986.

[46] P. Stoica and Y. Seln, "A review of information criterion rules," IEEE Signal Processing Magazine, vol. 21, no. 4, pp. 36-47, July 2004.

[47] M. Wax and T. Kailath, "Detection of signals by information theoretic criteria," IEEE Transactions on Acoustics, Speech and Signal Processing, vol. ASSP-33, no. 2, pp. 387-392, Apr. 1985.

[48] A. Ceban, R. Pusca, and R. Romary, "Study of rotor faults in induction motors using external magnetic field analysis," IEEE Transactions on Industrial Electronics, vol. 59, no. 5, pp. 2082-2096, May 2012.

[49] G. Houdouin, G. Barakat, B. Dakyo, E. Destobbeleer, and C. Nichita, "A coupled magnetic circuit based global method for the simulation of squirrel cage induction machines under rotor and stator faults," in Proceedings of ELECTRIMACS'02, Montreal (Canada), August 2002, pp. 18-21.

[50] A. Knight and S. Bertani, "Mechanical fault detection in a medium-sized induction motor using stator current monitoring," IEEE Transactions Energy Conversion, vol. 29, no. 4, pp. 753-760, December 2005.

[51] Z. Obeid, S. Poignant, J. Regnier, and P. Maussion, "Stator current based indicators for bearing fault detection in synchronous machine by statistical frequency selection," in Proceedings of the 2011 IEEE IECON 2011, Melbourne, Australia, Nov. 2011, pp. 2036-2041.

[52] R. R. Schoen and T. G. Habetler, "Effects of time-varying loads on rotor fault detection in induction machines," Industry Applications, IEEE Transactions on, vol. 31, no. 4, pp. 900-906, 1995.

[53] K. B. Petersen and M. S. Pedersen, "The matrix cookbook," November 2008. 


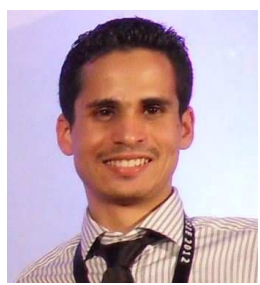

El Houssin El Bouchikhi was born in Khemisset, Morocco, in 1987. He received the Dipl.-Ing. and the M.Sc. degrees in automatic and electrical engineering, from the National Polytechnic Institute of Toulouse (INP-ENSEEIHT), Toulouse, France, in 2010, and the Ph.D. degree in electrical engineering in 2013 from the University of Brest, Brest, France. He is currently working at ISEN Brest as associate professor and an associate researcher member of the LBMS Lab (EA 4325). His current research interests are electrical machines fault detection and diagnosis through electrical quantities, especially in non-stationary operating conditions.

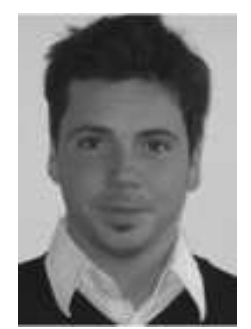

Vincent Choqueuse (M'08) was born in Brest, France, in 1981. He received the Dipl.-Ing. and the M.Sc. degrees in 2004 and 2005, respectively, from Troyes University of Technology, Troyes, France, and the Ph.D. degree in 2008 from the University of Brest, Brest, France. Since September 2009, he has been an Associate Professor with the Institut Universitaire de Technologie of Brest, University of Brest, Brest, France, and a member of the LBMS Lab (EA 4325). His research interests focus on signal processing and statistics for diagnosis and MIMO systems.

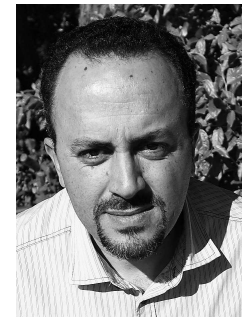

Mohamed El Hachemi Benbouzid (S'92-M'95-SM'98) was born in Batna, Algeria, in 1968. He received the B.Sc. degree in electrical engineering from the University of Batna, Batna, Algeria, in 1990, the M.Sc. and Ph.D. degrees in electrical and computer engineering from the National Polytechnic Institute of Grenoble, Grenoble, France, in 1991 and 1994, respectively, and the Habilitation à Diriger des Recherches degree from the University of Picardie "Jules Verne," Amiens, France, in 2000.

After receiving the Ph.D. degree, he joined the Professional Institute of Amiens, University of Picardie "Jules Verne," where he was an Associate Professor of electrical and computer engineering. Since September 2004, he has been with the Institut Universitaire de Technologie of Brest, University of Brest, Brest, France, where he is a Professor of electrical engineering. His main research interests and experience include analysis, design, and control of electric machines, variable-speed drives for traction, propulsion, and renewable energy applications, and fault diagnosis of electric machines.

Prof. Benbouzid is a Senior Member of the IEEE Power Engineering, Industrial Electronics, Industry Applications, Power Electronics, and Vehicular Technology Societies. He is an Associate Editor of the IEEE TRANSACTIONS ON ENERGY CONVERSION, the IEEE TRANSACTIONS ON INDUSTRIAL ELECTRONICS, the IEEE TRANSACTIONS ON SUSTAINABLE ENERGY, and the IEEE TRANSACTIONS ON VEHICULAR TECHNOLOGY. He was an Associate Editor of the IEEE/ASME TRANSACTIONS ON MECHATRONICS from 2006 to 2009. 